\title{
Zinc oxide nanosphere for hydrogen sulfide scavenging and ferroptosis of colorectal cancer
}

\author{
Xiang Pan ${ }^{1,4+}$, Yuchen $\mathrm{Qi}^{2 \dagger}$, Zhen Du ${ }^{2,6^{*}}$, Jian He${ }^{2}$, Sheng Yao ${ }^{4,5}$, Wei Lu' ${ }^{1}$, Kefeng Ding ${ }^{1,4^{*}}$ and Min Zhou ${ }^{1,2,3,4^{*}}$ (1)
}

\begin{abstract}
Background: Colorectal cancer is a common malignancy occurring in the digestive system and ranks second in cancer mortality worldwide. In colorectal cancer, hydrogen sulfide $\left(\mathrm{H}_{2} \mathrm{~S}\right)$ is selectively upregulated, resulting in the further exacerbation of the disease. Therefore, the clearance of $\mathrm{H}_{2} \mathrm{~S}$ and the regulation of the enzymes on the $\mathrm{H}_{2} \mathrm{~S}$ pathways are of great significance for colorectal cancer therapy.

Methods: Here, we investigated the $\mathrm{H}_{2} \mathrm{~S}$ content in various clinical tumor tissues from patients and confirmed that overproduced concentration of $\mathrm{H}_{2} \mathrm{~S}$ in colorectal cancer. Accordingly, we developed an $\mathrm{H}_{2} \mathrm{~S}$-responsive nanoplatform based on zinc oxide coated virus-like silica nanoparticles $(\mathrm{VZnO})$ for the therapy of colorectal cancer.

Results: Owing to its excellent $\mathrm{H}_{2} \mathrm{~S}$ scavenging ability, $\mathrm{VZnO}$ could effectively reduce $\mathrm{H}_{2} \mathrm{~S}$ content in colorectal cancer to prohibit the growth of CT26 and HCT116 colorectal cancer cells. Moreover, the removal of $\mathrm{H}_{2} \mathrm{~S}$ in colorectal cancer also leads to tumor inhibition through activating ferroptosis, a non-apoptotic form of cell death. The biosafety-related toxicological and pathological analysis confirmed the low toxicity and high safety of $\mathrm{VZnO}$ in colorectal cancer treatment. Furthermore, as an $\mathrm{H}_{2} \mathrm{~S}$-responsible nanosystem, $\mathrm{VZnO}$ appears to have no therapeutic effect on other non $\mathrm{H}_{2} \mathrm{~S}$ rich cancers, such as the $4 \mathrm{~T} 1$ breast cancer model.
\end{abstract}

Conclusions: We anticipate that the $\mathrm{H}_{2} \mathrm{~S}$-depletion-induced ferroptosis strategy using zinc oxide-based nanomaterials would provide insights in designing nanomedicines for colorectal cancer-target theranostics and may offer clinical promise.

Keywords: Zinc oxide nanoparticles, Hydrogen sulfide, Colorectal cancer, Ferroptosis, Nanoengineering, Glutathione

\section{Background}

Colorectal cancer (CRC), a common malignant tumor in the digestive system, ranks third in incidence and second in terms of mortality among the world. In 2020, more than 1.9 million new CRC cases and 935,000 deaths

\footnotetext{
*Correspondence: duzhen90@zju.edu.cn; dingkefeng@zju.edu.cn; zhoum@zju.edu.cn

${ }^{\dagger}$ Xiang Pan and Yuchen Qi contributed equally to this work

${ }^{1}$ Department of Colorectal Surgery and Oncology, Key Laboratory of Cancer Prevention and Intervention, Ministry of Education, The Second Affiliated Hospital, Zhejiang University School of Medicine, Hangzhou 310009, China

${ }^{6}$ The Cancer Hospital of the University of Chinese Academy of Sciences (Zhejiang Cancer Hospital), Institute of Basic Medicine and Cancer (IBMC), Chinese Academy of Sciences, Hangzhou, Zhejiang 310022, China

Full list of author information is available at the end of the article
}

were estimated to occur, representing about one in ten cancer cases and deaths [1]. Conventional CRC treatments include endoscopic and surgical local excision, radiotherapy and systemic chemotherapy [2]. The use of these treatments tends to produce large side effects and poor prognosis, which seriously affects the quality of life of CRC patients [3]. Therefore, it is necessary to further study the mechanism of CRC and develop safe and effective methods for the CRC treatment.

Hydrogen sulfide $\left(\mathrm{H}_{2} \mathrm{~S}\right)$ is a highly reactive endogenous gaseous signaling molecule that plays a crucial role in a variety of physiological functions [4], including activation of potassium channels [5], stimulation of kinase pathways [6], and inhibition of phosphodiesterase [7]. Recent studies have found that endogenous $\mathrm{H}_{2} \mathrm{~S}$ is closely related to original author(s) and the source, provide a link to the Creative Commons licence, and indicate if changes were made. The images or other third party material in this article are included in the article's Creative Commons licence, unless indicated otherwise in a credit line to the material. If material is not included in the article's Creative Commons licence and your intended use is not permitted by statutory regulation or exceeds the permitted use, you will need to obtain permission directly from the copyright holder. To view a copy of this licence, visit http://creativecommons.org/licenses/by/4.0/. The Creative Commons Public Domain Dedication waiver (http://creativeco mmons.org/publicdomain/zero/1.0/) applies to the data made available in this article, unless otherwise stated in a credit line to the data. 
the occurrence and development of CRC. As the important parts of the digestive system, the $\mathrm{H}_{2} \mathrm{~S}$ content in colorectal tissues tends to be higher than that in other normal tissues [8]. Due to the concentration dependence of $\mathrm{H}_{2} \mathrm{~S}$ physiological effects, the increased $\mathrm{H}_{2} \mathrm{~S}$ promotes the growth and progression of colorectal tumors, leading to higher mortality rates of CRC patients [9]. Classical research evidence demonstrated that cystathionine- $\beta$ synthase (CBS) is the key pathway for $\mathrm{H}_{2} \mathrm{~S}$ production, and the up-regulation of CBS increases the content of endogenous $\mathrm{H}_{2} \mathrm{~S}$ in the colorectal environment [10]. Therefore, using CBS inhibitors such as amino-oxyacetic acid (AOAA) can effectively reduce $\mathrm{H}_{2} \mathrm{~S}$ content in CRC by down-regulating $\mathrm{CBS}$, thus inhibiting the proliferation of CRC tumors [11]. However, CBS inhibitors represented by AOAA often affect multiple signaling pathways in the tumor, which is not conducive to the study of $\mathrm{H}_{2} \mathrm{~S}$ and CRC. Therefore, finding a method that can directly remove the $\mathrm{H}_{2} \mathrm{~S}$ in CRC is of great significance for the study of $\mathrm{H}_{2} \mathrm{~S}$ and CRC.

Inspiringly, with the explosive development of nanotechnology, some traditional biomedical difficulties are being solved. The special size and structure of nanomaterials endow them with unique physical and chemical properties, and make them easier to concentrate at the tumor site [12-14]. Therefore, we believe that appropriate nanomaterials can be selected to directly eliminate $\mathrm{H}_{2} \mathrm{~S}$ and thus be applied to the CRC treatment. In our previous study, a biocompatible nanosystem based on iron oxide-hydroxide nanospindles for magnetic resonance imaging (MRI) and $\mathrm{H}_{2} \mathrm{~S}$ based reaction-enhanced combinational CRC treatment is developed [15]. Furthermore, Lin et.al reported that an $\mathrm{H}_{2} \mathrm{~S}$-activated $\mathrm{Cu}_{2} \mathrm{O} @$ $\mathrm{CaCO}_{3}$ nanostructure responding to the endogenous $\mathrm{H}_{2} \mathrm{~S}$ and slightly acidic in the CRC microenvironment for CRC "turn-on" therapy [16]. These $\mathrm{H}_{2} \mathrm{~S}$ scavenging nanomaterials, mainly based on the metal oxide family $\left(\mathrm{Fe}_{3} \mathrm{O}_{4}\right.$ [17], $\mathrm{Cu}_{2} \mathrm{O}$ [18], $\mathrm{MnO}_{2}$ [19-21] and $\mathrm{ZnO}$ [22]), are expected to address the shortcomings of traditional CBS inhibitors because they act directly on endogenous $\mathrm{H}_{2} \mathrm{~S}$ molecules. Using $\mathrm{H}_{2} \mathrm{~S}$ to activate the diagnosis and therapy functions of intelligent theranostic agents has been considered an effective strategy to improve the treatment efficacy of CRC [16, 23]. However, the excessive functionality brings about the complexity of CRC research, and single-function nanomaterials that can effectively remove endogenous $\mathrm{H}_{2} \mathrm{~S}$ are required to realize the research on $\mathrm{H}_{2} \mathrm{~S}$ mediated CRC treatment.

Compared with other metal oxide desulfurizer, zinc oxide has outstanding desulfurization ability, high desulfurization accuracy, good stability, which makes it the most widely used desulfurizer in the industry [24]. Meanwhile, zinc oxide is relatively biocompatible and less toxic compared with other metal oxide nanoparticles, which further supports its potential biomedical applications [25]. Herein, we report an $\mathrm{H}_{2} \mathrm{~S}$-responsive nanoplatform based on zinc oxide coated virus-like silica $(\mathrm{VZnO})$ nanoparticles for CRC therapy. We found that the decrease of $\mathrm{H}_{2} \mathrm{~S}$ by $\mathrm{VZnO}$ leads to a significant decrease in intracellular glutathione (GSH) level, which eventually leads to ferroptosis in CRC cells. As a result, the $\mathrm{VZnO}$ nanoparticles could effectively suppress the growth of colorectal cancer (Scheme 1). Meanwhile, as an $\mathrm{H}_{2} \mathrm{~S}$-responsible nanosystem, $\mathrm{VZnO}$ appears to have no therapeutic effect on any other non $\mathrm{H}_{2} \mathrm{~S}$ rich cancers, such as the $4 \mathrm{~T} 1$ breast cancer model. Furthermore, the toxicological and pathological analysis confirmed the low toxicity and high safety of $\mathrm{VZnO}$ nanoparticles in CRC treatment. Our work may elucidate some of the mechanisms underlying $\mathrm{H}_{2} \mathrm{~S}$ scavenging, ferroptosis and CRC, and provide an effective strategy for the CRC treatment.

\section{Materials and methods \\ Human colorectal tissue samples}

Human primary CRC and uninvolved colorectal from the identical resection specimens were obtained by surgical resection and stored at $-80^{\circ} \mathrm{C}$ from 2018 to 2019 at The Second Affiliated Hospital, Zhejiang University School of Medicine. All experiments were approved by the Institutional Ethical Care and Use Committee of Zhejiang University. Informed consent was obtained from all patients, and experiments were performed in compliance with all relevant ethical regulations. No for in vivo animal study: AIRB-2021-952; Ref. No for in human dada: 2017-072.

\section{Materials}

Tetraethyl orthosilicate (TEOS, 99\%), hexamethylenetetramine (HMT, 99\%) and zinc nitrate hexahydrate $\left(\mathrm{Zn}\left(\mathrm{NO}_{3}\right)_{2} \cdot 6 \mathrm{H}_{2} \mathrm{O}, 99.95 \%\right)$, were purchased from Alfa Aesar Ltd. Hexadecyltrimethylammonium bromide $(\mathrm{CTAB})$ and fluorescein isothiocyanate (FITC) were purchased from Sigma-Aldrich. $\mathrm{NaOH}, \mathrm{Na}_{2} \mathrm{CO}_{3}$, cyclohexane, methanol and ethanol were supplied from the Beijing Chemical Reagent Company. All the chemical reagents were of analytical grade and used as received without further purification.

\section{Synthesis of zinc oxide coated virus-like silica nanoparticles}

The virus-like mesoporous silica nanoparticles (VMSN) were synthesized according to the literature with slight modification. In brief, $0.8 \mathrm{~mL}$ of $\mathrm{NaOH}(0.1 \mathrm{M})$, $850 \mathrm{mg}$ of CTAB and $60 \mathrm{~mL}$ of deionized water were added into a $100 \mathrm{~mL}$ round-bottom flask. The resulting solution was heated to $60{ }^{\circ} \mathrm{C}$ with constant stirring for $1.5 \mathrm{~h}$. Then $4 \mathrm{~mL}$ of TEOS and $16 \mathrm{~mL}$ of cyclohexane 


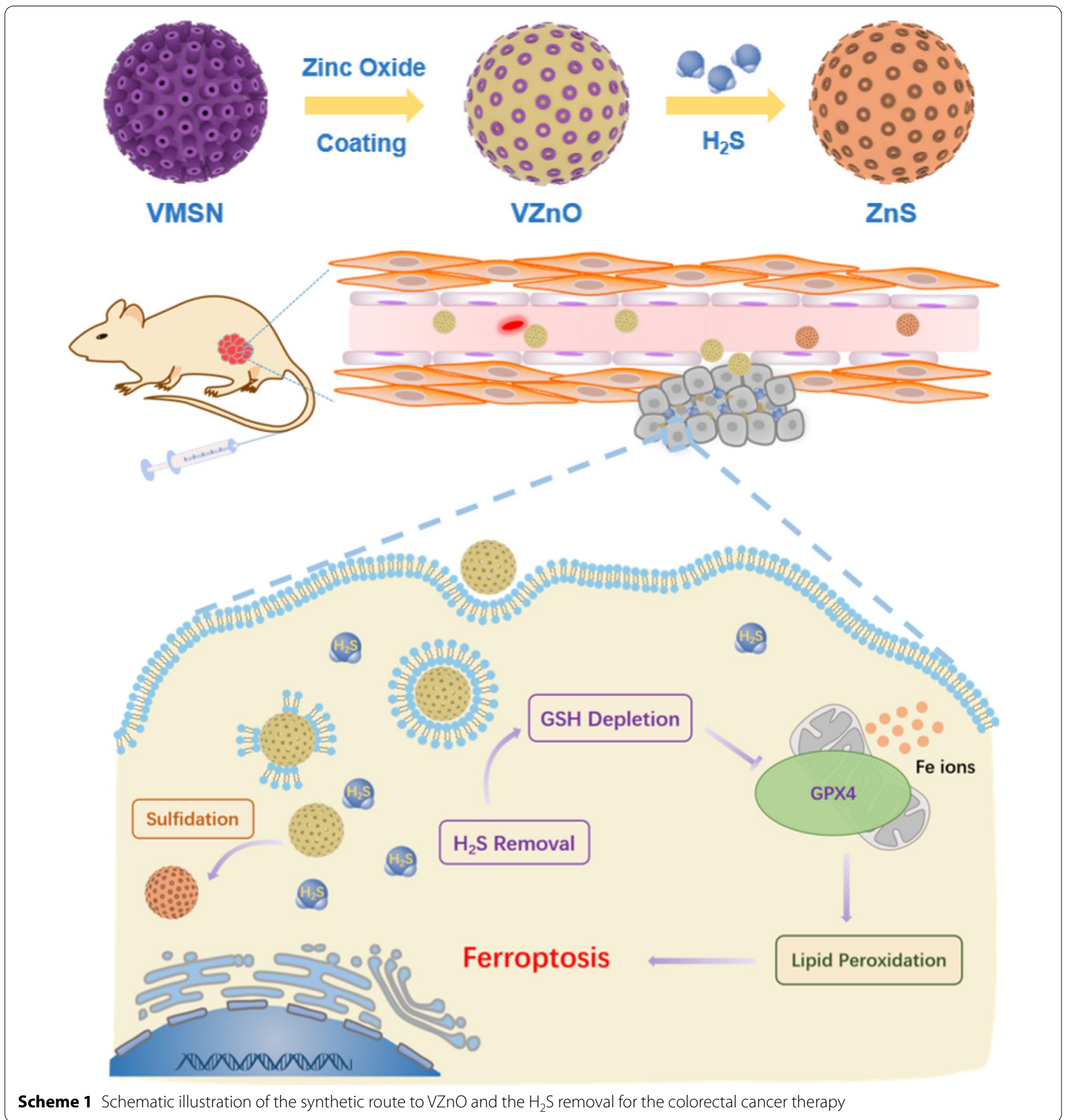

were mixed and cautiously added to the flask to form an oil layer. The reaction was kept at $60{ }^{\circ} \mathrm{C}$ with constant stirring and then cooled down after $48 \mathrm{~h}$ for the following treatment. The as-obtained silica nanoparticles were separated by centrifugation. The product was extracted with 1 wt \% solution of $\mathrm{NaCl}$ in methanol for $24 \mathrm{~h}$, repeated three times, to remove the CTAB. The as-obtained silica nanoparticles were collected by centrifugation, washed with ethanol and water, and finally dried through lyophilization.

In a typical procedure, $100 \mathrm{mg}$ VMSN, $230 \mathrm{mg}$ of $\mathrm{Zn}\left(\mathrm{NO}_{3}\right)_{2} \cdot 6 \mathrm{H} 2 \mathrm{O}$ and $50 \mathrm{~mL}$ of deionized water were added into a $100 \mathrm{~mL}$ round-bottom flask. After well mixed, $140 \mathrm{mg}$ of hexamethylenetetramine (HMT) was added to the aqueous dispersion under continuous stirring. The reaction was heated to $90{ }^{\circ} \mathrm{C}$ for $2 \mathrm{~h}$ and 
purified by centrifugation. The as-synthesized zinc oxide coated virus-like silica nanoparticles were washed with deionized water several times and dried through lyophilization, named $\mathrm{VZnO}$.

\section{FITC loading and stability study}

FITC was loaded on the VZnO by a soaking method. In brief, $20 \mathrm{mg}$ of $\mathrm{VZnO}$ was wholly dispersed in $6 \mathrm{~mL}$ ethanol solution of FITC $(0.5 \mathrm{mg} / \mathrm{mL})$ and stirred overnight under dark conditions. The nanocomposites were collected by centrifugation, washed with ethanol and PBS for three times and dried via lyophilization. The product was denoted as VZnO@FITC. The stability of VZnO@ FITC was researched by detecting the released amount of FITC with time. For determination, $10 \mathrm{mg}$ of VZnO@ FITC was redispersed in $20 \mathrm{~mL}$ of PBS buffer and stirred at $37{ }^{\circ} \mathrm{C}$ under dark conditions. After certain time intervals, $3 \mathrm{~mL}$ of the suspension was sucked out to centrifuge and the ultraviolet-visible (UV-vis) absorption of the supernatant was measured. The amounts of released FITC were calculated from the changes of the UV-vis absorbance.

\section{Characterization}

TEM (Tecnai F20, FEI, USA) was applied to characterize the morphology and size of the nanoparticles. The phase and crystal structure of the nanoparticles were collected by an X-ray diffraction instrument (XRD, X'Pert PRO MPD, The Netherlands) operated at $40 \mathrm{~mA}$ and $40 \mathrm{kV}$ using $\mathrm{Cu} \mathrm{K \alpha}$ radiation. Dynamic light scatting (DLS) and Zeta potential analysis were provided by Zetasizer NanoZSE (Malvern Instruments, U.K.). UV-vis spectra were recorded by a UV-2600 spectrophotometer (Shimadzu, Kyoto, Japan). Fluorescence spectra were acquired with an RF-6000 fluorescence spectrophotometer (Shimadzu, Kyoto, Japan). Surface area and pore size were measured by Surface Area and Porosity Analyzer (AUTOSORB-IQ2-MP, QUANTACHROME). Fourier transform infrared (FT-IR) spectra were collected using the Thermo Nicolet NEXUS 470 FTIR spectrophotometer with the $\mathrm{KBr}$ pellet technique.

\section{Sulfidation process of the VZnO nanoparticles}

$\mathrm{NaHS}$ was used to simulate endogenous hydrogen sulfide in the investigation of the sulfidation process of the $\mathrm{VZnO}$ nanoparticles. An aqueous dispersion of $\mathrm{VZnO}$ nanoparticles ( $35 \mathrm{mM}$, based on $\mathrm{Zn}$ element) was added to the NaHS solution $(30 \mathrm{mM})$ at room temperature. After $2 \mathrm{~h}$ of incubation, the product was collected by centrifugation and washed twice with water. The obtained nanoparticles were characterized by X-ray diffraction (XRD), UV-vis and DLS.

\section{Assay of $\mathrm{H}_{2} \mathrm{~S}$ generation}

To detect the generation of $\mathrm{H}_{2} \mathrm{~S}$ in intestinal tissue of patients and mice, a unisense $\mathrm{H}_{2} \mathrm{~S}$ microsensor (a miniaturized amperometric sensor with guard electrode) (Model $\mathrm{H}_{2} \mathrm{~S}-\mathrm{MRCh}$, Unisense, Aarhus, Denmark) coupled to a unisense picoampere amplifier was used. $0.1 \mathrm{~g}$ Tissue (wet weight) was homogenized in $1 \mathrm{~mL}$ ice-cold potassium phosphate buffer $(0.05 \mathrm{M})$. Adding $5 \mathrm{~mL}$ $\mathrm{NaOH}(1 \mathrm{M})$ and $5 \mathrm{~mL} 10 \%$ trichloroacetic acid to the central hole of the reaction bottle, the reaction bottle is blown $30 \mathrm{~s}$ by $\mathrm{N}_{2}$ before sealing. A thermostatic table concentrator initiated the reaction for $2 \mathrm{~h}$ at $37^{\circ} \mathrm{C}$. Finally, the reaction system was incubated at $37^{\circ} \mathrm{C}$ for $2 \mathrm{~h}$ to terminate the reaction. The concentration of $\mathrm{H}_{2} \mathrm{~S}$ in the solution was determined by the sensitive sulfur electrode method in the central hole. The rate of $\mathrm{H}_{2} \mathrm{~S}$ formation was calculated.

\section{Western Blot}

$20 \mu \mathrm{g}$ of protein extract was loaded on a 10\% gel (PAGE Gel Fast Preparation Kit, EpiZyme-NP0321) and transferred to a polyvinylidene difluoride membrane. The membrane was incubated in $0.1 \%$ TBST with $5 \%$ non-fat dry milk (Blocker ${ }^{\mathrm{TM}}$ BLOTTO in TBS, Thermo-37530) for $2 \mathrm{~h}$ at room temperature. Primary antibodies were used at the following dilutions: rabbit-anti-GPX4 (SigmaSAB4300725) 1:2000; rabbit-anti-CBS (Sigma-AV45746) 1:4000; rabbit-anti-COX2 (Sigma-SAB4200576) 1:5000; goat-anti-NOX1 (Sigma-SAB2501686) 1:5000; rabbit-anti-TRF1 (Sigma-SAB4502943) 1:500; rabbit-antiGAPDH (Invitrogen-PA1-987) 1:3000; rabbit-anti-GGCT (Invitrogen-PA5-80,658) 1:1000; rabbit-anti-RRM1 (Invitrogen-PA5-75,989) 1:1000; rabbit-anti-RRM2 (Invitrogen-PA5-27,856) 1:1000. The membrane was washed with $0.1 \%$ TBST for $10 \mathrm{~min}$ (three times) at room temperature and followed by incubation in secondary antibody for $2 \mathrm{~h}$ at room temperature. Secondary antibodies: Goat anti-Rabbit IgG (Invitrogen-A31460), dilution 1:10,000; and Rabbit anti-Goat IgG (Invitrogen-A31402), dilution 1:10,000. The membrane was washed with $0.1 \%$ TBST for $10 \mathrm{~min}$ (three times) at room temperature. Antigen complexes were visualized and quantified with the Odyssey Infrared Imaging System (LI-COR).

\section{Immunohistochemistry}

H\&E stained tumor sections were stained using standard histological techniques. Immunohistochemistry was conducted using rabbit-anti-CBS (Sigma-AV45746) 1:4000. Last, slices were photographed with a Virtual slide microscope (Olympus VS120, Japan). The photographs were analyzed with the Image-Pro Plus 6.0 software (Media Cybernetics Inc., Silver Spring, MD, USA). Secondary 
antibodies: Goat-anti-rabbit IgG (Invitrogen-32460), dilution 1:60.

\section{Cell viability}

The following cell lines were used in the study: HCT116, SW480, HT29 (all human colon cancer cells), MC38, CT26 (all mouse colon cancer cells), NCM460 (normal human colon mucosal epithelial cell), SKOV3 (human ovarian cancer cells), 4T1 (mouse breast cancer cells), MCF-10A (normal human breast epithelial cell), H1299 (human non-small cell lung cancer cell), B16F10 (murine melanoma cell). All the cell lines were purchased from American Type Culture Collection (ATCC). HCT116 were cultured in 1640 and CT26 were cultured in DMEM with $10 \%$ FBS and $1 \%$ antibiotics $(100 \mathrm{U} / \mathrm{mL}$ penicillin and $100 \mu \mathrm{g} / \mathrm{mL}$ streptomycin) at $37{ }^{\circ} \mathrm{C}$ in a $5 \% \mathrm{CO}_{2}$ atmosphere. $1 \times 10^{5} \mathrm{CT} 26$ and HCT116 were separately seeded in a 96-well plate and incubated with $\mathrm{VZnO} /$ iron-dextrin (ID)/ ferrostatin-1 (Fer-1)/GSH at predetermined concentrations for $24 \mathrm{~h}$. Cell viability was measured using the standard 3-(4,5-dimethylthiazol2-yl)-2, 5-diphenyltetrazolium bromide (MTT) assay kit (YEASEN, Shanghai, China).

\section{Detection of reactive oxygen species}

HCT116 and CT26 were seeded in 6-well plates at a density of $8 \times 10^{3}$ cells per well and were incubated overnight, then treated with or without ID/VZnO for $24 \mathrm{~h}$. Then the cells were stained with a DCFH-DA assay kit (YEASEN, Shanghai, China) or C-11 BODIPY $(2 \mu \mathrm{M})$ and imaged under a fluorescence microscope (Zeiss, Oberkochen, Germany). The evaluation of generated reactive oxygen species (ROS) was further quantified by fluorescence microscope.

\section{Animal study}

Balb/c athymic nude mice (5-6 weeks old) were purchased from the Shanghai SLAC Laboratory Animal Company. All animal experiments were approved by the Institutional Animal Care and Use Committee of Zhejiang University. To establish an orthotopic colon cancer model, CT26 transfected with luciferase (CT26/Luc) $\left(2.0 \times 10^{6}\right.$ cells, $\left.50 \mu \mathrm{L}\right)$ in PBS were carefully injected into the cecal wall of mice under anesthesia by isoflurane (RWD Life Science). To establish an orthotopic breast model, 4T1 transfected with luciferase (4T1/Luc) $\left(2.0 \times 10^{6}\right.$ cells, $\left.50 \mu \mathrm{L}\right)$ in PBS were carefully injected into the fourth pair of breast fat pads of mice. After a week, mice with CRC model were successfully established for fluorescence imaging. For mice toxicity studies in nude mice, mice were treated with $\mathrm{VZnO} / \mathrm{ID} / \mathrm{PBS}$ as described in the results. Mouse body weights were measured 2-3 times per week. At the end of the experiments, mice were euthanized, and blood and main organs were collected for analysis. The toxicity studies, including hematology, chemistry analyses, were performed by the Zhejiang Chinese Medical University Laboratory Animal Research Center.

\section{TEM analysis of tumor tissues}

The sample was first fixed with $2.5 \%$ glutaraldehyde in phosphate buffer $(0.1 \mathrm{M}, \mathrm{pH} 7.0)$ for more than $4 \mathrm{~h}$; washed three times in the phosphate buffer for $15 \mathrm{~min}$ at each step; then postfixed with $1 \% \mathrm{OsO}_{4}$ in phosphate buffer for 1-2 $\mathrm{h}$ and washed three times in the phosphate buffer (for $15 \mathrm{~min}$ at each step. Then the sample was first dehydrated by a graded series of ethanol $(30 \%$, $50 \%, 70 \%, 80 \%, 90 \%$ and $95 \%$ ) for about $15 \mathrm{~min}$ at each step, then dehydrated by alcohol for $20 \mathrm{~min}$. In the end, transferred to absolute acetone for $20 \mathrm{~min}$. The specimen was placed in a 1:1 mixture of absolute acetone and the final Spurr resin mixture for $1 \mathrm{~h}$ at room temperature, then transferred to a 1:3 mixture of absolute acetone and the final resin mixture for $3 \mathrm{~h}$, and ultimately placed in final Spurr resin mixture for overnight. Then, the specimen was transferred in Eppendorf containing Spurr resin and heated at $70{ }^{\circ} \mathrm{C}$ for more than $9 \mathrm{~h}$. The specimen was sectioned in ultratome (LEICA-EM UC7) and sections were stained by uranyl acetate and alkaline lead citrate for 5-10 min respectively and observed in TEM (Hitachi Model H-7650).

\section{RNA-sequencing}

The total RNA was extracted from HCT116 treated with $\mathrm{VZnO} / \mathrm{ID}$ and control cells. The transcript was sequenced using the BGISEQ-500 sequencing platform (BGI Teeh Company, China). After rRNA depletion, the RNA fragments were reversely transcribed into cDNA by using an N6 random primer. The $5^{\prime}$ end of cDNA was phosphorylated, and $3^{\prime}$ end of cDNA was modified with stickiness "A". Then, the cDNA was ligated with the adapter with sticky " $T$ " at the $3^{\prime}$ end. Two specific primers are utilized to amplify the ligation DNA products. The DNA products were denatured by heat, and the singlestranded DNA was circularized by DNA ligase. Finally, the prepared DNA library was sequenced. Bowtie2 software was used to map clean reads to the reference gene, and HISAT software was utilized to map to the reference genome. Genes with a $\log 2$ fold change $\geq 1$ were considered differentially expressed. The gene ontology analysis was carried out by the online program NetworkAnalyst (www.networkanalyst.ca).

\section{H\&E staining}

Murine-derived tumor tissue and main organs were embedded in optimal cutting temperature (OCT) 
compound (SAKURA-4583), flash frozen and kept at $-80{ }^{\circ} \mathrm{C}$ until cutting. For $\mathrm{H} \& \mathrm{E}$ staining, slides were fixed in ice-cold acetone for $10 \mathrm{~min}$, then immersed in filtered Harris modified Hematoxylin solution (Abcam-ab220365) for $5 \mathrm{~min}$, then rinsed with tap water. The slides were dehydrated in ascending alcohol solutions $(70 \%, 80 \%, 95 \%$, and $100 \%)$ and cleared with xylene (Aladdin-1330-20-7) for $1 \mathrm{~min}$ each. Finally, the results of H\&E staining were observed by a fluorescence microscope.

\section{Protein extraction from cells and tissues}

For protein extraction from cells, cell pellets were lysed buffer (Beyotime-P0013B) after rinsed by pre-cooling $\mathrm{PBS}$, for $30 \mathrm{~min}$ at $4{ }^{\circ} \mathrm{C}$ on a rotary shaker. For protein extraction from intact or decellularized tissues, $0.5 \mathrm{~g}$ of freshly dissected tissue was disrupted at $4{ }^{\circ} \mathrm{C}$ using a homogenizer. Protein concentration was determined using the BCA protein assay kit (23225; Thermo Fisher Scientific). All protein suspensions were kept at $0{ }^{\circ} \mathrm{C}$ until use.

\section{Glutathione detection}

GSH was measured by using a Total Glutathione Assay Kit (Beyotime Institute of Biotechnology) according to the manufacturer's protocol. Absorbance was measured at $412 \mathrm{~nm}$ and the result was calculated as $\mathrm{nmol} /$ mg protein.

\section{Fluorescence microscopy examination of lipid peroxidation} with C11-BODIPY

Before the experiment, cells were seeded in a confocal culture dish $(2 \times 105$ cells per dish). After incubation for $24 \mathrm{~h}$, the old medium was aspirated, followed by the addition of fresh culture medium. After another $6 \mathrm{~h}$ incubation, the culture medium was aspirated, and the resulting cells were washed twice with PBS. Next, MCF-7 were stained with $1 \mathrm{~mL}$ of C11-BODIPY $(10 \mu \mathrm{M})$ at $37^{\circ} \mathrm{C}$ for $20 \mathrm{~min}$. Finally, the resulting cells were washed again with PBS 3 times, and further observed under confocal fluorescence microscopy.

\section{Statistical analysis}

Results are expressed as the mean \pm standard deviation unless otherwise stated. Statistical differences among experimental groups were analyzed by Student's $t$-test. $P<0.05$ was considered statistically significant. All statistical calculations were performed using GraphPad Prism 6, including assumptions of tests used (GraphPad Software Inc, CA, USA).

\section{Results and discussion}

\section{The overproduction of $\mathrm{H}_{2} \mathrm{~S}$ in human CRC}

It has been reported that $\mathrm{H}_{2} \mathrm{~S}$ plays a vital role in inflammatory response and CRC development [26-29]. To explore the role of $\mathrm{H}_{2} \mathrm{~S}$ in $\mathrm{CRC}$, we first examined the concentration of $\mathrm{H}_{2} \mathrm{~S}$ in human CRC specimens (Additional file 1: Table S1) and several typical CRC cells (HCT116, CT26, HT29, and MC38). As shown in Fig. 1A, the specific expression of $\mathrm{H}_{2} \mathrm{~S}$ in CRC human specimens was significantly higher than that in normal colorectal tissues and aside colorectal tumor tissues. Furthermore, $\mathrm{H}_{2} \mathrm{~S}$ is obviously overproduced in CRC cells compared to non-CRC cell lines, including MCF-10A normal human breast epithelial cells, SKOV3 ovarian cancer cells, and $4 \mathrm{~T} 1$ breast cancer cells (Fig. 1B). We then found that $\mathrm{H}_{2} \mathrm{~S}$ was consistently overexpressed at different stages of CRC development (Fig. 1C), and there was no significant difference in $\mathrm{H}_{2} \mathrm{~S}$ expression between different stages of CRC patients (Additional file 1: Fig. S1). It is worth noting that the content of $\mathrm{H}_{2} \mathrm{~S}$ in normal human colorectal mucosal epithelial cells is significantly higher than that in non-colon cell lines (Fig. S2). Since endogenous $\mathrm{H}_{2} \mathrm{~S}$ in CRC is mainly produced from CBS [13], we studied the up-regulation of CBS in human CRC specimens compared with the patient-matched normal colorectal tissue by Western Blot and Immunohistochemistry (Fig. 1D, E). Similar CBS expression trends were also observed in normal colon cells and colon cancer cell lines (Fig. 1F). Then we use AOAA, a hydrogen sulfide synthase inhibitor, to block the $\mathrm{H}_{2} \mathrm{~S}$-producing activity of CBS in HCT116 and CT26 (Fig. 1G). After the treatment of AOAA, both cell viability (Fig. $1 \mathrm{H}$ ) and cell growth (Fig. 1I and Additional file 1: Fig S3) of HCT116 and CT26 demonstrated significant inhibiting effects.

\footnotetext{
(See figure on next page.)

Fig. 1 The overproduction of $\mathrm{H}_{2} \mathrm{~S}$ in human $\mathrm{CRC}$. A, $\mathbf{B} \mathrm{H}_{2} \mathrm{~S}$ production measured in human colorectal cancer specimens ${ }^{*} P<0.05 \mathrm{vs}$. normal mucosa) and in colorectal cancer cell lines ( ${ }^{*} P<0.05$ vs. NCM460 cells; n.s.: no significant difference v.s. MCF-10A) by the $\mathrm{H}_{2} \mathrm{~S}$ microsensor. (T: tumor tissue; A: aside colorectal tumor tissue; $\mathrm{N}$ : normal colorectal tissue). $\mathrm{CH}_{2} \mathrm{~S}$ production in different stage of human colorectal cancer specimens measured by the $\mathrm{H}_{2} \mathrm{~S}$ microsensor. D Western Blot of CBS protein expression in human colorectal cancer specimens, paired with the adjacent tissue and corresponding normal mucosa tissues. Membranes are re-probed for GAPDH expression to show that similar amounts of protein were loaded in each lane. $\mathbf{E}$ Immunohistochemistry of CBS protein expression in human colorectal cancer specimens, paired with the adjacent tissue and corresponding normal mucosa tissues. F Western Blot of CBS protein expression in colon cancer cell lines (vs. NCM460). G $\mathrm{H}_{2} \mathrm{~S}$ production is measured in colon cancer cell lines treated by AOAA. H Cell viability of the HCT116 and CT26 treated with AOAA for $24 \mathrm{~h}$. I Cell growth of the HCT116 and CT26 treated with AOAA within 6 days. $(* P<0.05)$, (n.s.: No significant difference, $P$ value $>0.05)$
} 

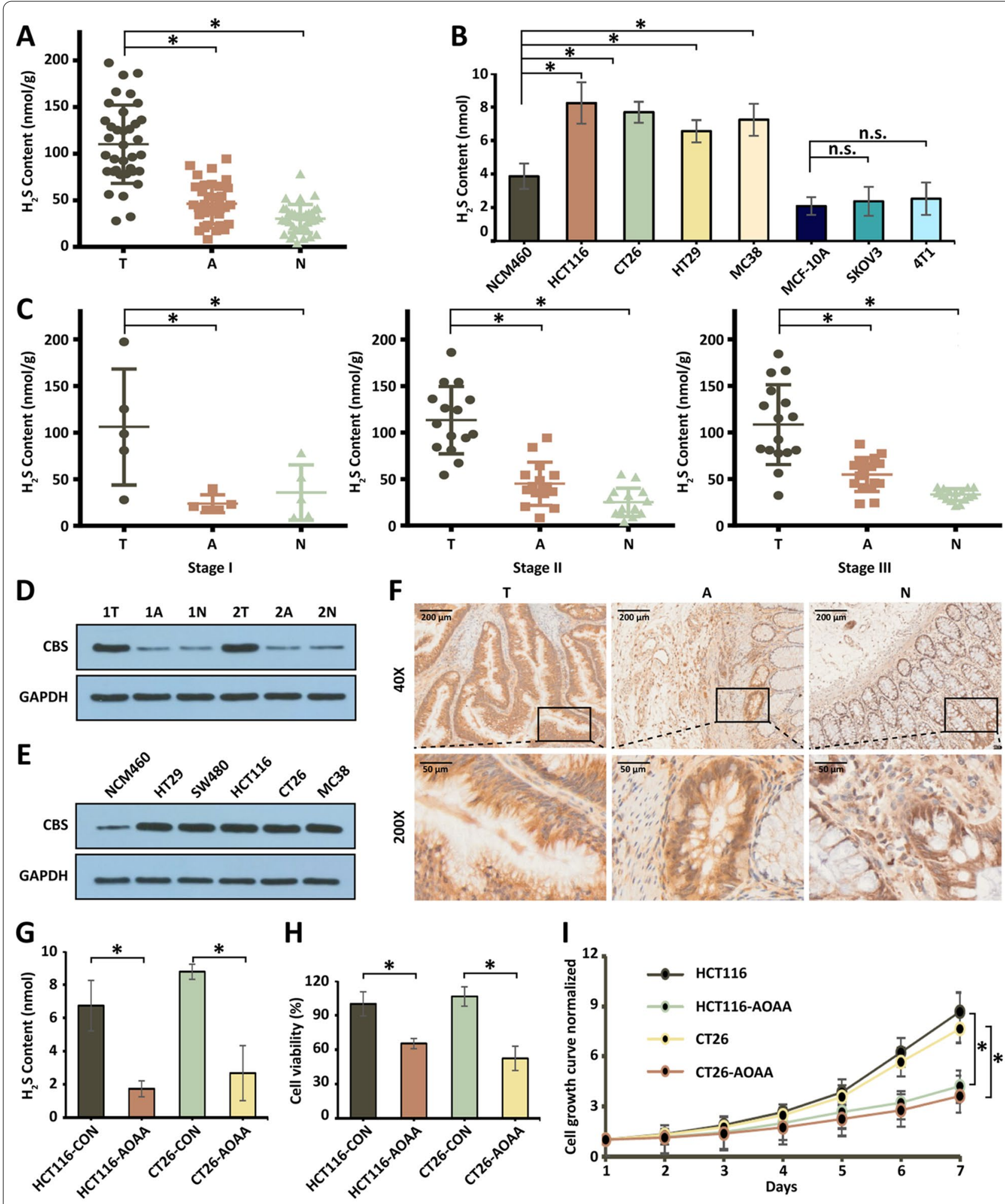

Fig. 1 (See legend on previous page.) 


\section{Preparation and characterization of VZnO}

In addition to CBS-derived, $\mathrm{H}_{2} \mathrm{~S}$ is mainly a product of cysteine metabolism among many compounds produced by intestinal microorganisms in the metabolic activities of amino acids, which has exerted influences on the metabolism, physiology and physiological pathology of the host colonic mucosa [30]. Mesoporous materials have attracted extensive research interest because of their large specific surface area, large pore volume, uniform and orderly mesopores, and rich skeleton structure [31]. Taking advantage of the excellent ability of zinc oxide to remove hydrogen sulfide, we decided to develop an $\mathrm{H}_{2} \mathrm{~S}$-responsive $\mathrm{VZnO}$ nanoplatform for CRC therapy.

The synthetic route of the VZnO nanosphere was illustrated in Scheme 1. Firstly, the virus-like mesoporous silica nanoparticles with monodispersed size $(\approx 120 \mathrm{~nm})$ and surrounding surface morphology were synthesized as templates (Fig. 2A, Additional file 1: Fig. S4). Then, the zinc oxide layer was successfully deposited in situ on the surface of VMSN, leading to the formation of VMSN@ $\mathrm{ZnO}$ nanoparticles (Fig. 2B, C). The elemental mapping images showed that $\mathrm{Si}$ and $\mathrm{O}$ elements were homogeneously distributed in the core of the $\mathrm{VZnO}$ nanoparticles, while the $\mathrm{Zn}$ element was homogeneously distributed in the shell of the nanoparticles (Fig. 2D). The XRD patterns confirmed that the crystal structure of the VZnO nanoparticles agreed well with the standard zinc oxide (JCPDS No. 036-1451) (Fig. 2E). In addition, DLS studies revealed a monodisperse size distribution for $\mathrm{VZnO}$ with an average diameter of $203 \mathrm{~nm}$ (Fig. 2F). Nitrogen adsorption - desorption experiments showed that VZnO has a Brunauer - Emmett - Teller (BET) surface area of $241 \mathrm{~m}^{2} \mathrm{~g}^{-1}$ and a median pore size of $3.23 \mathrm{~nm}$ (Fig. 2G). The mesoporous structure and negative Zeta potential make VZnO an excellent drug carrier. Here, FITC was loaded into the $\mathrm{VZnO}$ by a soaking method, yielding VZnO@FITC for the real-time fluorescence imaging of the nanoparticles (Additional file 1: Fig. S5).

\section{Sulfidation of VZnO}

As a classical desulfurized, zinc oxide exhibits outstanding $\mathrm{H}_{2} \mathrm{~S}$ scavenging ability. The chemical reaction between zinc oxide and hydrogen sulfide is illustrated by the following equation.

$$
\mathrm{ZnO}(\mathrm{s})+\mathrm{H}_{2} \mathrm{~S}(\mathrm{~g}) \rightarrow \mathrm{ZnS}(\mathrm{s})+\mathrm{H}_{2} \mathrm{O}(\mathrm{g})
$$

zinc oxide can react with surrounding gaseous $\mathrm{H}_{2} \mathrm{~S}$ efficiently to consumes $\mathrm{H}_{2} \mathrm{~S}$ while generates zinc sulfide as the product. $[32,33]$. Thus, the ingredient of $\mathrm{VZnO}$ before and after the sulfuration reaction was confirmed first. To simplify the research work, NaHS was chosen as the sulfur source to simulate the endogenous $\mathrm{H}_{2} \mathrm{~S}$ gas. After the reaction with $\mathrm{NaHS}$, the XRD patterns of $\mathrm{VZnO}$ showed prominent zinc oxide peaks disappear and zinc sulfide peaks appear, indicating that $\mathrm{VZnO}$ was vulcanized into ZnS (Fig. 2E). Meanwhile, the UV-vis absorption of $\mathrm{VZnO}$ increased significantly within $350 \mathrm{~nm}$ after the sulfuration reaction process (Fig. $2 \mathrm{H}$ ). With the VMSN as the core, the morphology of $\mathrm{VZnO}$ did not change significantly after a short time sulfidation reaction (Additional file 1: Fig S6). The above results indicate that $\mathrm{VZnO}$ reacts with $\mathrm{H}_{2} \mathrm{~S}$ to form $\mathrm{ZnS}$. The above results indicate that $\mathrm{VZnO}$ exhibits outstanding $\mathrm{H}_{2} \mathrm{~S}$ reactivity, making it a promising candidate for CRC therapy.

\section{The $\mathrm{H}_{2} \mathrm{~S}$ scavenging of $\mathrm{VZnO}$ in $\mathrm{CRC}$}

It has been reported that $\mathrm{H}_{2} \mathrm{~S}$ plays an important role in GSH biosynthesis [34, 35]. Therefore, we studied the effect of $\mathrm{H}_{2} \mathrm{~S}$ clearance on CRC cells by studying the changes of GSH. GSH is a major intracellular antioxidant factor that inhibits ROS-dependent p38/MAPK activation by reducing ROS levels [23]. According to the report, GSH and GSH metabolizing enzymes are present at elevated levels in colonic tumors [36-38]. However, the regulatory mechanism of $\mathrm{H}_{2} \mathrm{~S}$ on glutathione in human CRC cell lines and tissues remains unelucidated. At first, we detected the total GSH levels in HCT116 and CT26 after VZnO treatment for $24 \mathrm{~h}$. GSH levels in HCT116 and CT26 are significantly reduced after $\mathrm{H}_{2} \mathrm{~S}$ is removed (Fig. 3A). Following treatment with $\mathrm{VZnO}$ for $24 \mathrm{~h}$, the cell viability of both the HCT116 and CT26 was decreased via the MTT based cell viability assay. Moreover, the rescue experiment showed that GSH reversed the $\mathrm{VZnO}$-induced decline in cell viability (Fig. 3B). And we evaluated the effect of $\mathrm{VZnO}$ on cell viability of $4 \mathrm{~T} 1$ or MCF-10A or SKOV3 from $24 \mathrm{~h}$. We did not observe a significant decrease of cell viability $24 \mathrm{~h}$ after treatment, indicating the negligible cytotoxicity of $\mathrm{VZnO}$. (Additional file 1: Fig. S7).

GSH deficiency, an essential antioxidant in mammalian cells, leads to an increase in intracellular ROS. Then, we elevated ROS levels in HCT116 and CT26 after $24 \mathrm{~h}$ treatment with $\mathrm{VZnO}$ (Fig. 3C). We found that $\mathrm{VZnO}$ can reduce the total intracellular GSH content by scavenging $\mathrm{H}_{2} \mathrm{~S}$.

\section{The ferroptosis of cancer cells}

After GSH depletion, glutathione peroxidase 4 (GPX4) activity decreases, and lipid oxides cannot be metabolized by GSH reductase catalyzed by GPX4, ultimately contributing to ferroptosis [39, 40]. GSH provides electrons to the critical regulator of ferroptosis, GPX4, which is one of the most efficient enzymes for reducing lipid peroxides $(-\mathrm{OOH})$ in membranes to their corresponding alcohols $(-\mathrm{OH})[41,42]$. The occurrence of ferroptosis is always accompanied by a series of changes at the 

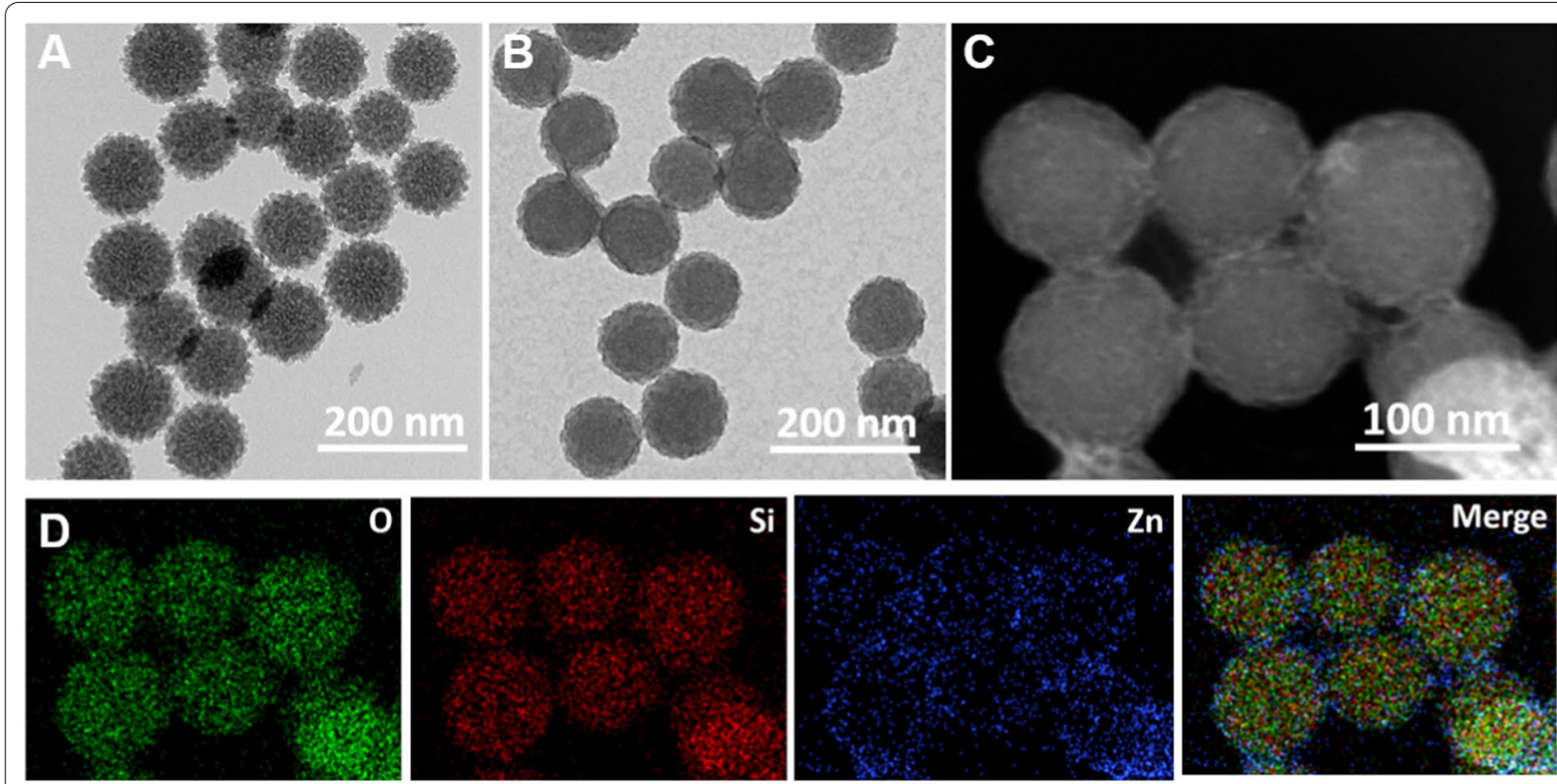

E

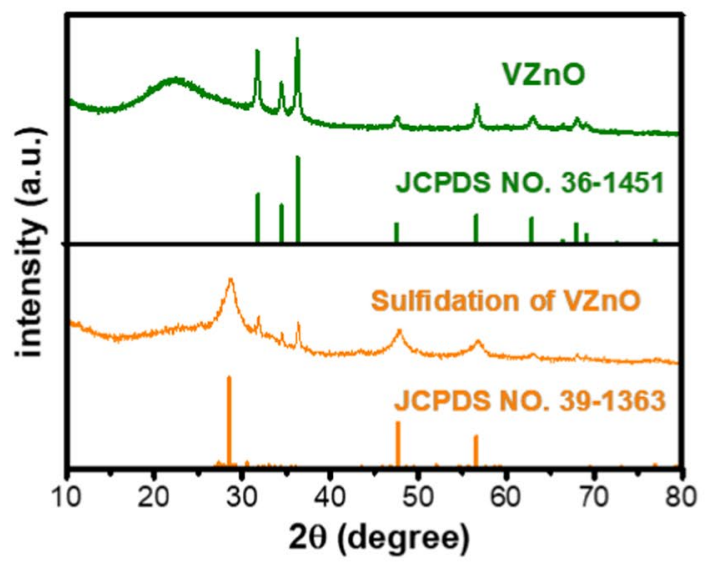

G

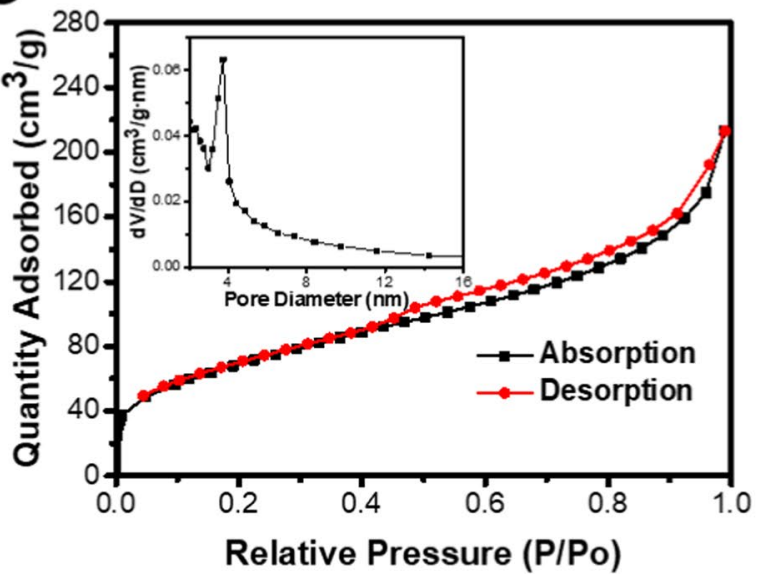

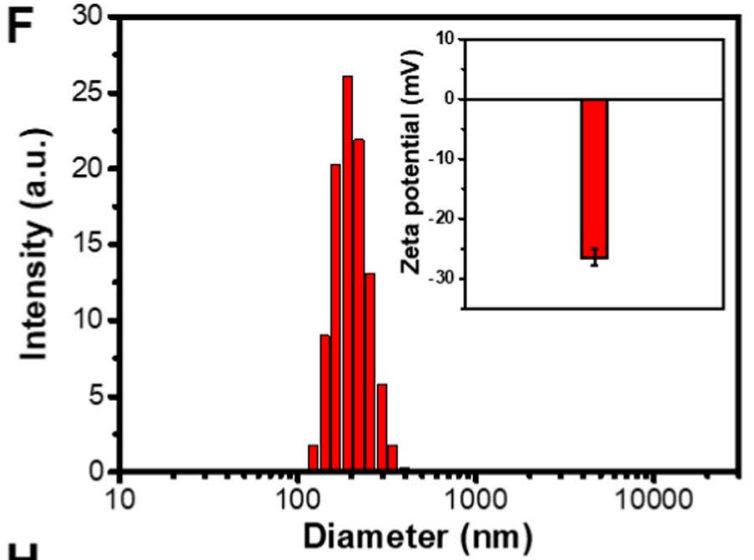

$\mathrm{H}$

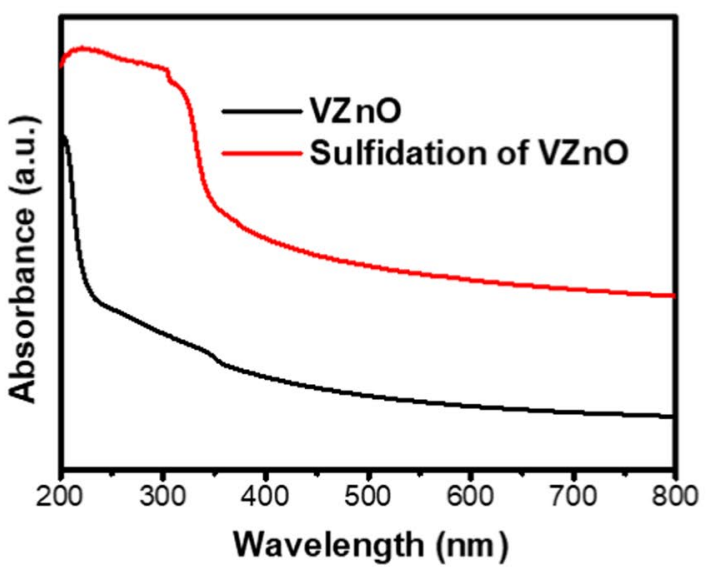

Fig. 2 Preparation and characterization of VZnO. A, B TEM images of original VMSN template and VZnO nanoparticles, respectively. C, D HAADF-STEM image and corresponding elemental mapping of VZnO nanoparticles. E XRD patterns of the VZnO nanoparticles before and after sulfidation reaction, respectively. F Size distribution of the VZnO from DLS analysis. Inset: zeta potential of the nanoparticles. G Nitrogen adsorptiondesorption curves of the VZnO nanoparticles. Inset: Pore-size distribution curve of the VZnO nanoparticles. $\mathbf{H}$ UV-vis absorption spectrum of VZnO nanoparticles before and after sulfidation reaction, respectively 
cellular, molecular, and genetic levels similar and different from other forms of cell death [43, 44]. Ferroptosis phenotypes were determined primarily by observing the iron-dependent accumulation of ROS combined with morphological changes at the cellular and subcellular levels $[45,46]$. Evaluation of molecules associated with ferroptosis, such as labile iron, ROS, and glutathione, provides a means of monitoring the process of ferroptosis in vivo and in vitro. Protein and genetic analysis led to a deeper understanding of ferroptosis [47, 48]. Ferroptosis is associated with dramatic morphological changes of mitochondria, including mitochondrial fragmentation and decreased number of cristae $[49,50]$. In this part, we used some experiments that focus on the characteristics and biomarkers of ferroptosis.

To further verify that ferroptosis occurred, we found that the cell viability of HCT116 and CT26 was further decreased treated with VZnO and ID $(100 \mu \mathrm{M})$ (Fig. 3B). Moreover, after HCT116 and CT26 were treated with $\mathrm{VZnO}$ and ID for $24 \mathrm{~h}$, a DCFH-DA assay kit was used to detect intracellular ROS levels. Green fluorescence was significantly enhanced, indicating that intracellular ROS levels were increased (Fig. 3C). Using the fluorescent probe C11-BODIPY, we observed a significant increase in lipid oxidation prior to cell death in HCT116 and CT26 treated with $\mathrm{VZnO}$ and ID for $24 \mathrm{~h}$ (Fig. 3D). TEM images (Fig. 3E) revealed structural aberrations of mitochondria (the red arrow in Fig. 3E) in malignant epithelial cells, including mitochondria smaller than normal cells and mitochondrial membrane shrinkage, as well as reduction and disappearance of mitochondrial cristae, even without impaired membrane integrity (Fig. 3F). Reduced GPX4 levels and enhanced expression levels of NOX1, COX2 and TFR1 were observed in HCT116 and CT26 treated with $\mathrm{VZnO}$ and ID for $24 \mathrm{~h}$, suggesting ferroptosis is activated (Fig. 3G). These all indicated that ferroptosis was activated in HCT116 and CT26 after $\mathrm{H}_{2} \mathrm{~S}$ was removed by $\mathrm{VZnO}$ and ID.

\section{In vivo and ex vivo biodistribution of $\mathrm{VZnO}$}

Nanoparticles typically enter tumors through the enhanced osmotic and retention (EPR) effect, through which the nanomaterial passes through openings between or within the endothelial cells of the blood vessels and exudes into the gaps [51, 52]. According to our previous study results, $\mathrm{H}_{2} \mathrm{~S}$ in CRC specificity significantly increased (Fig. 1B) [15]. Thus, we expect that $\mathrm{VZnO}$ would improve CRC target efficacy owing to excellent specificity. We have detected $\mathrm{H}_{2} \mathrm{~S}$ content in tumors in the orthotopic CRC model. To further demonstrate the distribution of the material in the body, we intravenously injected VZnO@FITC into the Balb/c mice, which were examined by an in vivo imaging system. The fluorescence signals in the tumor were detected at $0.5 \mathrm{~h}$ after injection of VZnO@FITC, reached a peak at $4 \mathrm{~h}$, and then gradually decreased to the basal level at $48 \mathrm{~h}$ (Fig. 4A-C). We collected tissues and performed in vitro fluorescence imaging for further verification. Compared with most normal tissues, except the liver, the tumor tissues had the highest uptake of VZnO@FITC, as evidenced by the fluorescence signals of major organs at various time points in the biodistribution study (Fig. 4D, E).

\section{Biosafety of VZnO}

$\mathrm{ZnO}$ nanoparticles are widely utilized for different diseases [43]. At present, the biological toxicity of nano-sized zinc oxide has not been concluded. As nanoparticles' fundamental material properties, particle size is one of the main factors affecting their reactivity and cytotoxicity [53]. To examine the potential toxicity, $\mathrm{Balb} / \mathrm{c}$ mice were treated with $\mathrm{VZnO}(50 \mathrm{mg} / \mathrm{kg})$ and ID $(50 \mathrm{mg} / \mathrm{kg})$, twice a week for 4 weeks. Administration of treatment by these dosing regimens causes no apparent systemic toxicity as assessed by body weight (Fig. 4F). For example, no significant changes were observed in the counts of red or white blood cells in treated versus control mice. The number of ALT and AST were slightly increased in VZnO-treated mice compared with the control. VZnO also had no significant effect on creatinine, blood urea nitrogen (Fig. 4G). Altogether, $\mathrm{VZnO}$ is well tolerated in immune-competent mice.

\section{Anti-tumor activity of VZnO}

We next evaluated the therapeutic potential of $\mathrm{VZnO}$ $(50 \mathrm{mg} / \mathrm{kg})$ and ID $(50 \mathrm{mg} / \mathrm{kg})$ using the orthotopic CRC model. The anticancer efficacy of $\mathrm{VZnO}$ and ID was evaluated in the orthotopic CRC model by monitoring the tumor burden. Bioluminescence imaging was used

(See figure on next page.)

Fig. 3 The $\mathrm{H}_{2} \mathrm{~S}$ scavenging and tumor ferroptosis induced by VZnO in CRC. A The GSH detected by total glutathione assay kit in HCT1 16 and CT26 after VZnO and ID treatments. B Cell viability by MTT assay in HCT116 and CT26 after VZnO, ID, GSH and Fer-1 treated. C Intracellular ROS levels measured by DCFH-DA assay kit in HCT116 and CT26 with or without VZnO and ID treated. D Colocalization of oxidized lipid and nucleus co-stained by BODIPY C11 (green) and DAPI (blue) in HCT116 and CT26 cells. E Representative picture of the ultrastructure of mitochondria in HCT116 and CT26 after VZnO and ID treated. F Average number of mesenchymal cristae per mitochondrion in VZnO-treated cells (statistics of 20 mitochondria) G Representative GPX4, COX2, NOX1 and TFR1 protein expression by Western Blot in HCT116 and CT26 with or without VZnO and ID treated. Membranes were re-probed for GAPDH expression to show that similar amounts of protein were loaded in each lane. $\left({ }^{*} P<0.05\right)$, (n.s.: No significant difference, $P$ value $>0.05$ ) 

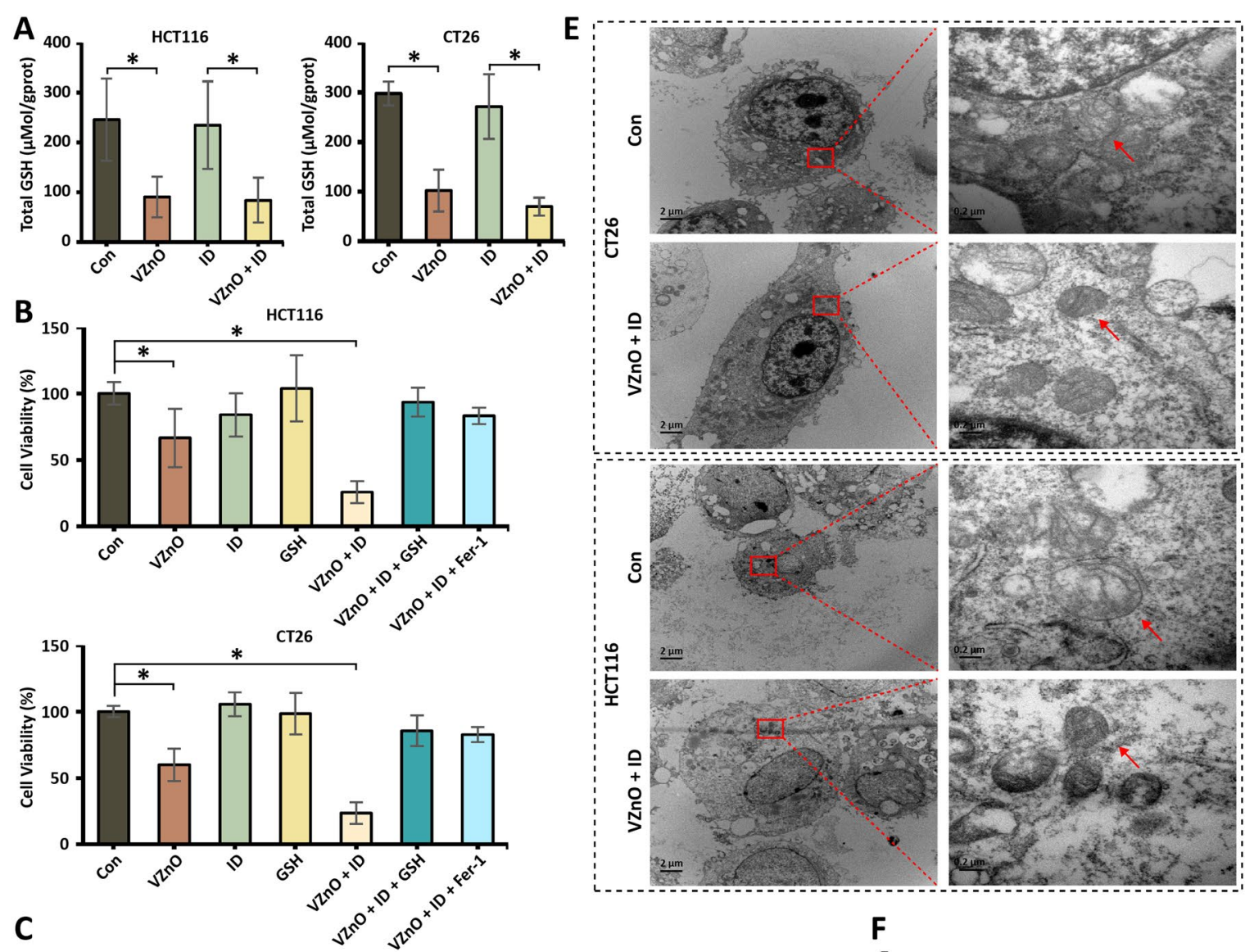

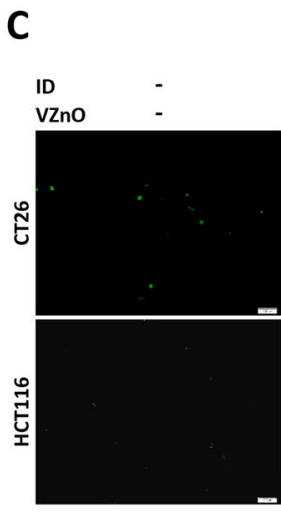

D

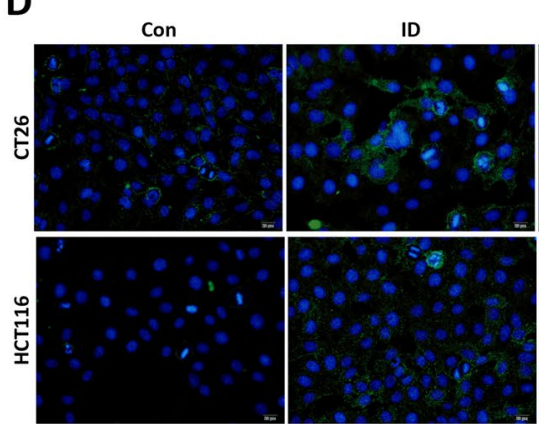

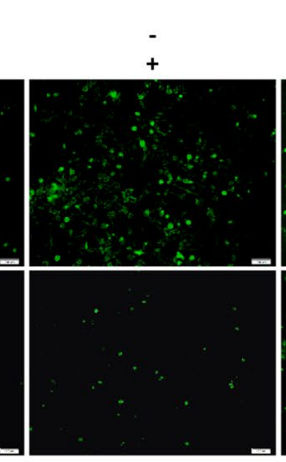

VZno

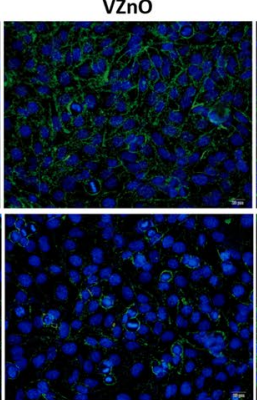

VZno + ID

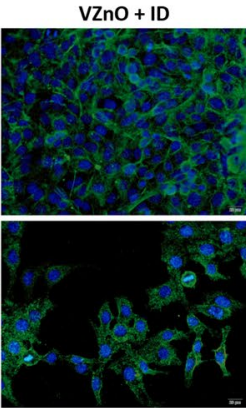

$\mathbf{F}$

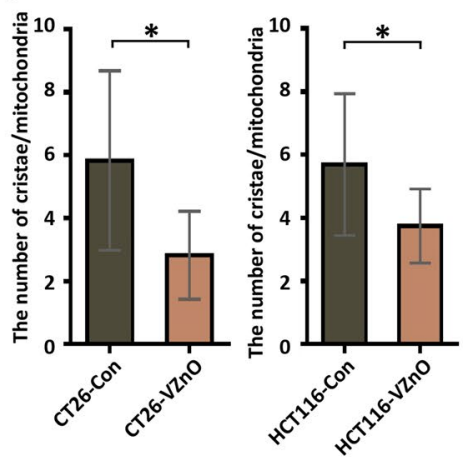

G

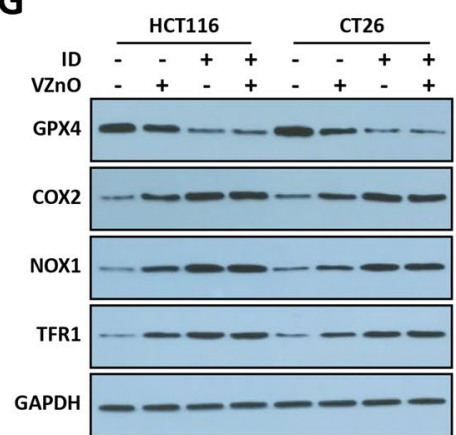

Fig. 3 (See legend on previous page.) 

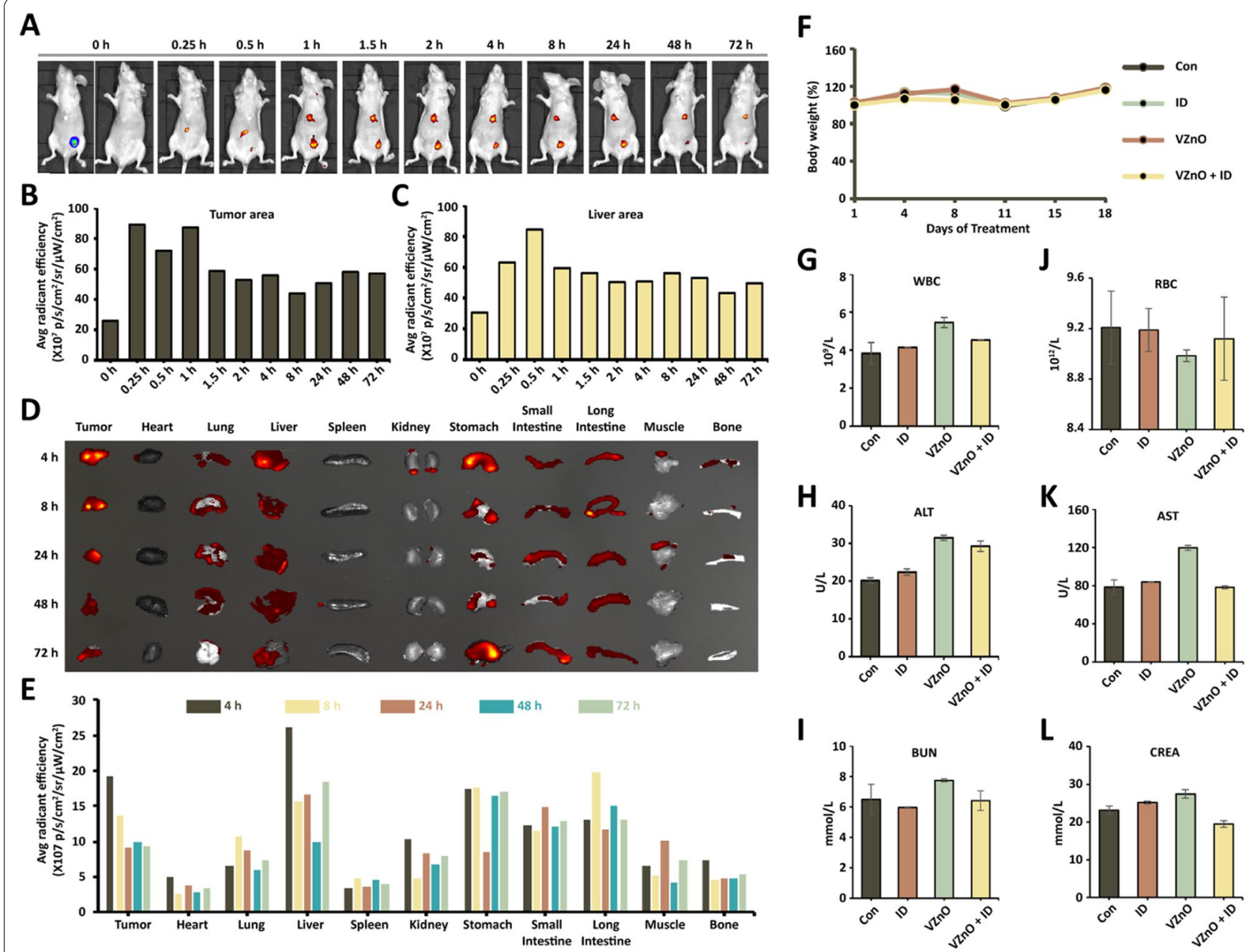

Fig. 4 Biodistribution and biosafety of VZnO. A In vivo fluorescence imaging of VZnO@FITC in orthotopic CRC tumor after intravenous injection. B, C The representitive quantitative analysis of the tumor and liver tissues, respectively. D, E ex vivo imaging and the representitive quantitative analysis. F The body weight of Balb/c mice treated with VZnO. G-L Routine blood, biochemical, liver, and kidney function levels of Balb/c mice on day 14

to assess the therapeutic efficacy in real-time and noninvasively (Fig. 5A). Because CT26 express luciferases, the bioluminescent intensity of the cells can be used to qualify the survival of the cancer cells. Nude mice bearing CRC were administered PBS, VZnO and ID, respectively. The bioluminescent intensities from the animals were quantified. Among the treatment groups, the combination therapy of $\mathrm{VZnO}$ and ID achieved better control of tumor growth, as evidenced by the lowest luciferase activities observed at the end of treatment (day 14) (Fig. 5B-D) and body weight (Fig. 5F). However, VZnO and ID lacked a specific antitumor effect in the orthotopic breast model (low hydrogen sulfide content) (Fig. 5J, Additional file 1: Fig. S8). Immunohistochemistry staining of tumors show combination therapy had the lowest tumor cell density, and no significant abnormalities were

(See figure on next page.)

Fig. 5 Anti-tumor activity of $\mathrm{VZnO}$ in orthotopic CRC model. A Experimental timeline of the orthotopic CRC model. B Bioluminescence imaging of orthotopic colon cancer mouse injected with different treatments on day 14. C, D Photograph and volume of the tumors with different treatments on day 14. E Representative H\&E stained of liver and tumor tissue on day 14. F Body weights of orthotopic colon cancer model. G The continuously $\mathrm{H}_{2} \mathrm{~S}$ production in mouse model. H Representative GPX4, COX2, NOX1 and TFR1 protein expression by Western Blot in tumor on day 14. Membranes were re-probed for GAPDH expression to show that similar amounts of protein were loaded in each lane. I) $\mathrm{H}_{2} \mathrm{~S}$ content measured on day 14 . $\mathbf{J}$ The volume of the tumors in the orthotopic breast model on day 14. $\left.{ }^{*} P<0.05\right)$, (n.s.: No significant difference, $P$ value $>0.05$ ) 
A

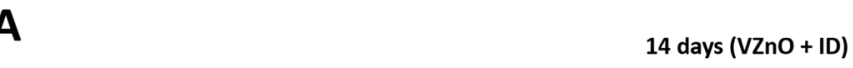

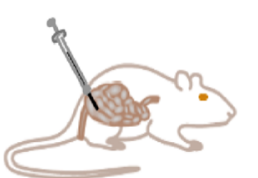

Tumor inoculation

B

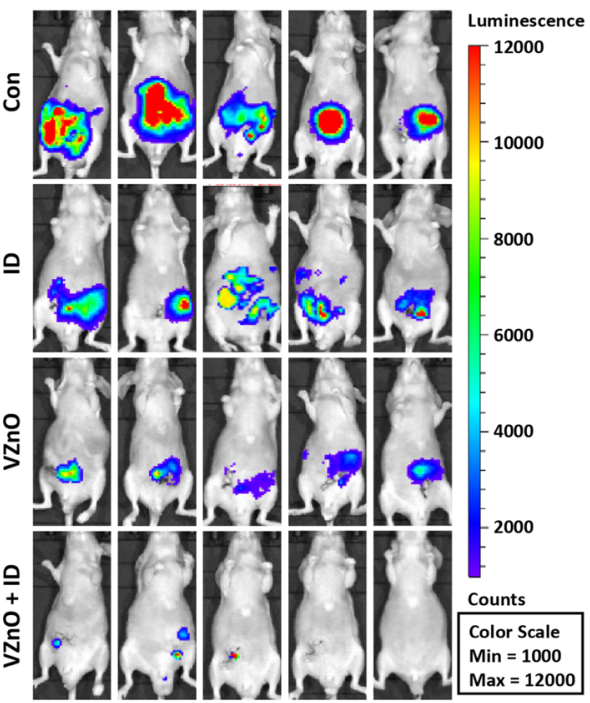

$\mathbf{F}$

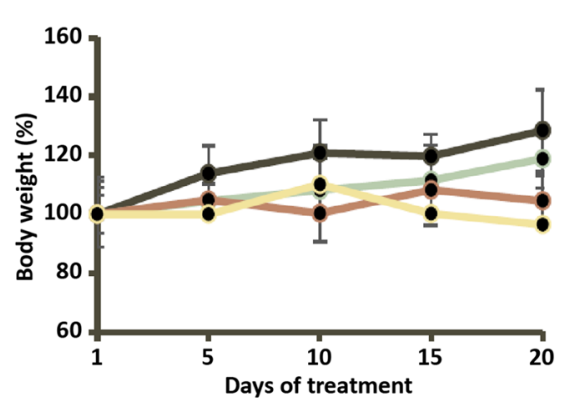

H

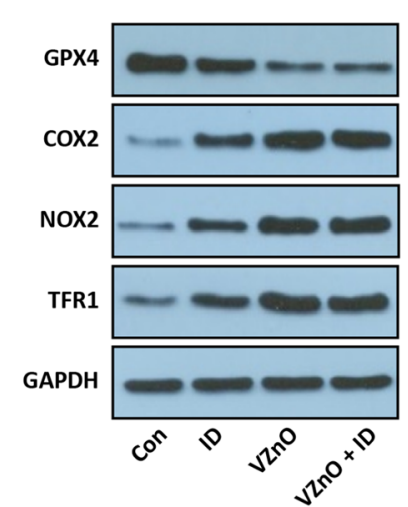

I

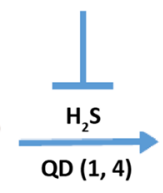

VZnO (i.v.)

\begin{abstract}
C
\end{abstract}
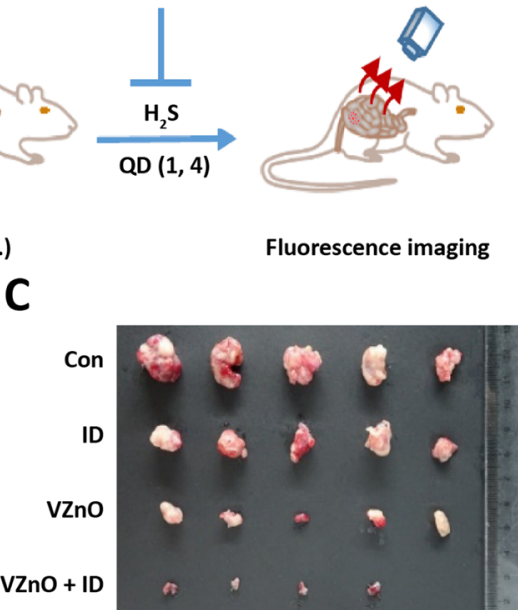

Fluorescence imaging

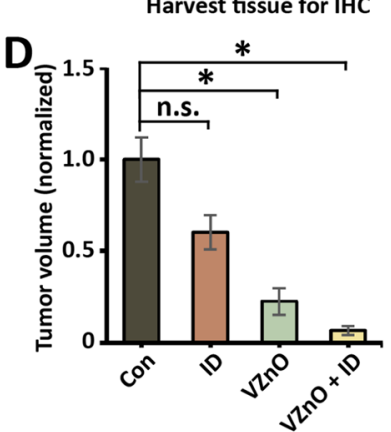

E

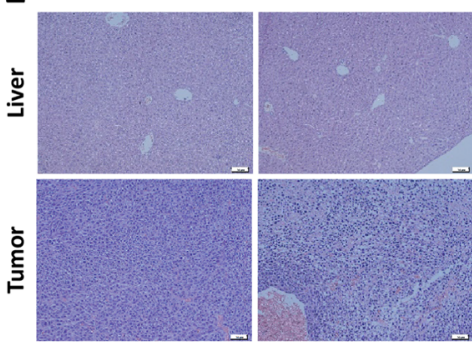

${ }^{\text {con }} \mathbf{G}$

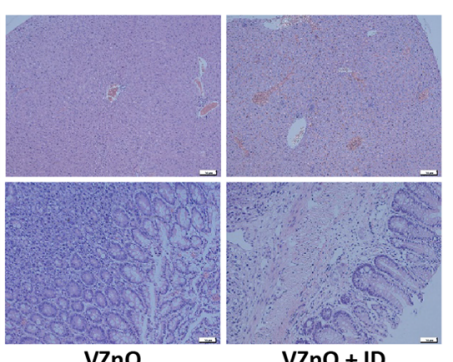

$\mathrm{VZnO}+\mathrm{ID}$
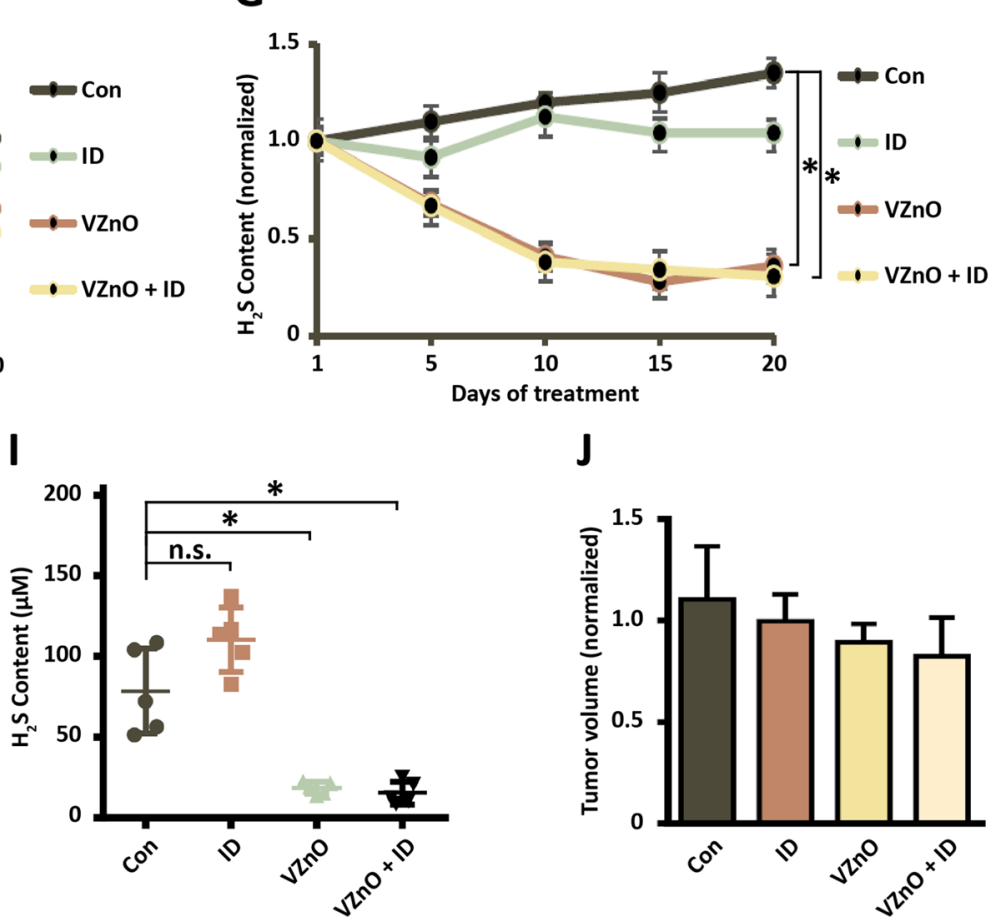

J

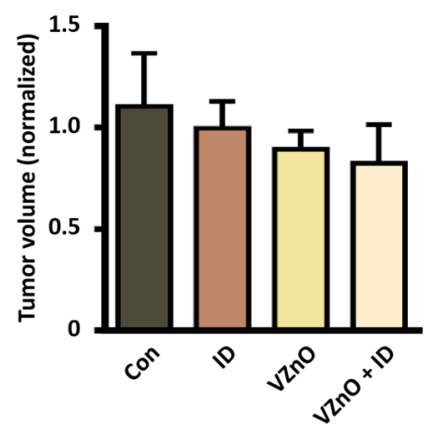

Fig. 5 (See legend on previous page.) 

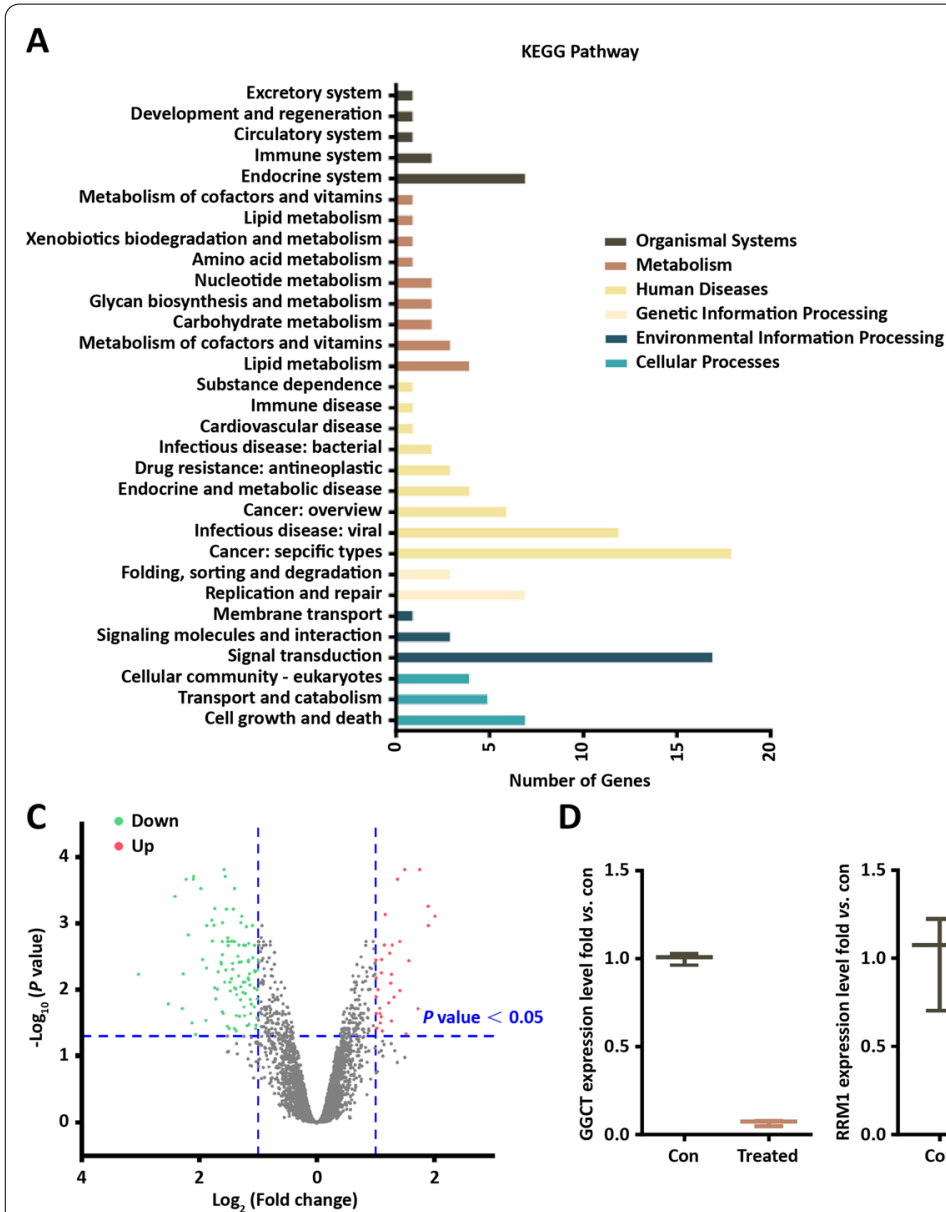

D
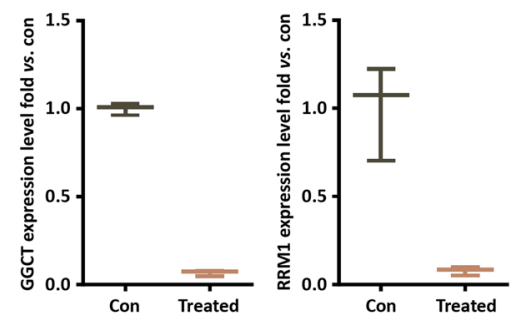

B
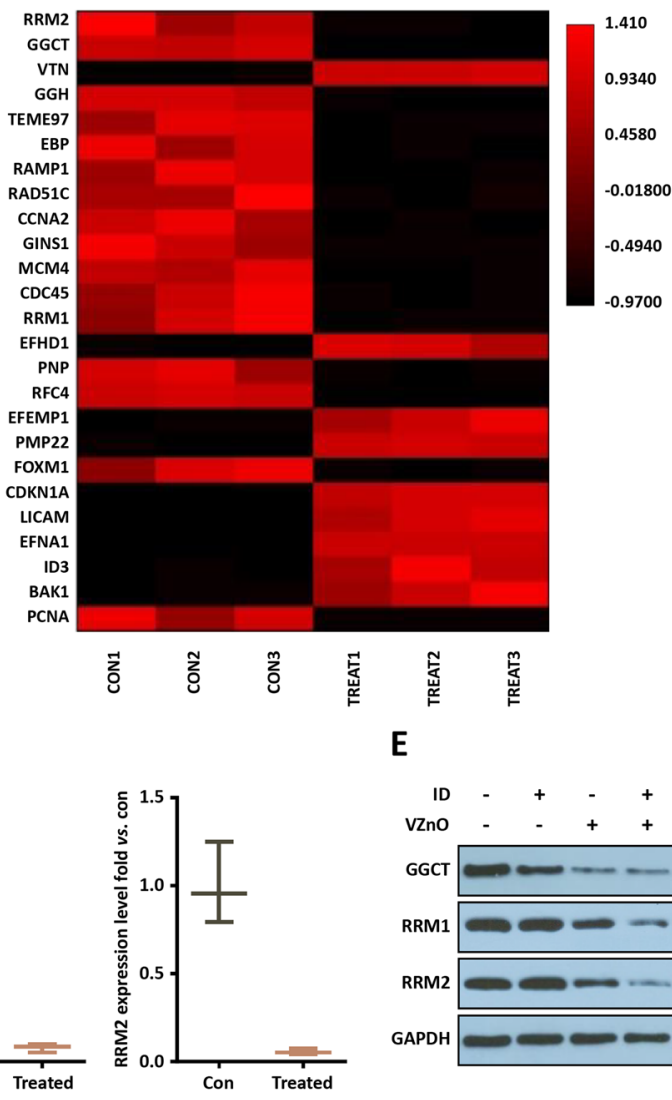

Fig. 6 Transcriptome analysis in VZnO-treated HCT116. A KEGG pathway analysis based on the RNA-seq results in HCT116. B Representative heatmap of gene expression levels. C Representative scatter plot of 140 significant genes (33 unregulated genes marked in red and 107 downregulated genes marked in green) for Treat vs. Con. D mRNA levels of GGCT, RRM1 and RRM2 by RNA-seq. E Representative Western Blot result of GGCT, RRM1 and RRM2. Membranes were re-probed for GAPDH expression to show that similar amounts of protein were loaded in each lane

found in the liver, lung, spleen, and heart (H\&E staining) (Fig. 5E, Additional file 1: Fig. S9).

To evaluate the changes within the tumor after treatment by $\mathrm{VZnO}$ and ID. Comparison of tumor tissue in CRC model treated with or without $\mathrm{VZnO}$ and ID revealed the selective up-regulation of the ferroptosisassociated protein COX2, NOX1 and TFR1 and downregulation of GPX4 (Fig. 5H), consistent with previous cell experiments. Following, we proved the content of $\mathrm{H}_{2} \mathrm{~S}$ is declined in tumor of CRC model treated with VZnO and ID (Fig. 5I), and the concentration of $\mathrm{H}_{2} \mathrm{~S}$ has been reduced to a minimum after about four treatments (Fig. 5G).

\section{Transcriptome analysis in VZnO-treated HCT116}

When ferroptosis are known to mark critical aspects of tumor therapy, global changes could have broad consequences in transcriptomics. To further explore the underlying molecular mechanisms of ferroptosis activated after treatment, the RNA-seq based transcriptome analysis to be used as estimated the transcriptome changes in HCT116 among the control and VZnO/ID groups. There were 33 genes upregulated and 107 genes downregulated in the $\mathrm{VZnO} / \mathrm{ID}$-treat group compared with the control group (Fig. 6A, C). Kyoto Encyclopedia of Genes and Genomes (KEGG) pathway analysis showed that these genes were related to cellular motility, growth and death, etc. Among these genes, we found gamma-glutamylcyclotransferase (GGCT), may play a critical role in glutathione homeostasis, whose expression was strongly downregulated after treatment (Fig. 6B, D). Moreover, ribonucleotide reductase M1 (RRM1) and ribonucleotide reductase M2 (RRM2) are also involved in glutathione metabolic pathways according to KEGG pathway analysis (Fig. 6D). And the results were verified by Western Blot (Fig. 6E). 


\section{Conclusion}

In summary, we have successfully developed an $\mathrm{H}_{2} \mathrm{~S}$-responsive $\mathrm{VZnO}$ nanoplatform for CRC therapy. As a recognized desulfurized, $\mathrm{ZnO}$ exhibits outstanding $\mathrm{H}_{2} \mathrm{~S}$ scavenging ability and could effectively reduce the $\mathrm{H}_{2} \mathrm{~S}$ content in the colorectum. The VZnO nanoparticles can be used as tumor intracellular $\mathrm{H}_{2} \mathrm{~S}$ scavengers to induce cell death via ferroptosis with ID. Importantly, $\mathrm{VZnO}$ reacts with $\mathrm{H}_{2} \mathrm{~S}$ in tumors and efficiently consumes GSH in tumor cells. We found that the tumor cell death was driven by lipid peroxidation, called ferroptosis, after the VZnO reduced the GSH level. We offer evidence linking targeted $\mathrm{H}_{2} \mathrm{~S}$ discovery in CRC with ferroptosis, implicating $\mathrm{H}_{2} \mathrm{~S}$ is a therapeutic target for $\mathrm{CRC}$. These results may provide a rationale for considering $\mathrm{H}_{2} \mathrm{~S}$ clearance as a means to be implicated in CRC. The research is limited, but it does show some promising future therapeutic targets for tumors. At the same time, we also proved that $\mathrm{VZnO}$ aggregate at tumor sites in vivo and have good biosafety to immunocompetent Mice. Concordantly, we found that systemic depletion of $\mathrm{H}_{2} \mathrm{~S}$ by $\mathrm{VZnO}$ in adult mice caused no overt toxicity. This is indicated that $\mathrm{VZnO}$ has good biosafety. This therapeutic target warrants further investigation.

Our study has several important implications. First, it provides an example that nanomaterial technology can turn an essentially undruggable target such as $\mathrm{H}_{2} \mathrm{~S}$ into a druggable target, thus paving the way for the many human diseases in which $\mathrm{H}_{2} \mathrm{~S}$ plays a critical role. Second, it proposed the significance of $\mathrm{H}_{2} \mathrm{~S}$ in the tumor and suggested that excessive $\mathrm{H}_{2} \mathrm{~S}$ in tumors may be selfprotective and harmful to surrounding normal tissues. Third, we performed a biosafety-related toxicological pathology analysis to ensure that the combination of $\mathrm{VZnO}$ therapy targeting tumors has low toxicity and high safety. In summary, we provide robust evidence supporting $\mathrm{VZnO}$ as a selective and efficient $\mathrm{H}_{2} \mathrm{~S}$ scavenger for colorectal cancer treatment. Our research provides a solid foundation for the clinical development of $\mathrm{H}_{2} \mathrm{~S}$ scavenging agents for $\mathrm{H}_{2} \mathrm{~S}$-relative human cancer and other human diseases. We believe that this design approach will advance the development of materials for tumor-specific therapy with less toxicity and side effects on normal tissues.

\section{Supplementary Information}

The online version contains supplementary material available at https://doi. org/10.1186/s12951-021-01069-y.

Additional file 1: Supplementary data to this article can be found online including Materials, additional Experimental Methods of in vitro and in vivo.

\section{Acknowledgements}

Thanks for the technical support by the Core Facility, Zhejiang University School of Medicine.

\section{Authors' contributions}

$M Z, K D$, and ZD designed the experiments. $X P, Y Q$, and ZD performed the experiments, prepared the figures and wrote the manuscript. JH, SY, and WL provided technical support. All authors read and approved the final manuscript.

\section{Funding}

This work was supported by the National Natural Science Foundation of China (Nos. 81971667, 32000994), the Key Research and Development Projection of Zhejiang Province (No. 2020C03035), and the Fundamental Research Funds for the Zhejiang Provincial Universities (No. 2021XZZX034). We gratefully acknowledge the Core Facility of Zhejiang University School of Medicine for the technical support.

\section{Availability of data and materials}

All data generated or analyzed during this study are included in this manuscript and its Additional file 1.

\section{Declarations}

Ethics approval and consent to participate

Not applicable.

\section{Consent for publication}

Not applicable.

\section{Competing interests}

The authors declare that they have no competing interests.

\section{Author details}

${ }^{1}$ Department of Colorectal Surgery and Oncology, Key Laboratory of Cancer Prevention and Intervention, Ministry of Education, The Second Affiliated Hospital, Zhejiang University School of Medicine, Hangzhou 310009, China. ${ }^{2}$ Institute of Translational Medicine, Zhejiang University, Hangzhou 310029, China. ${ }^{3}$ State Key Laboratory of Modern Optical Instrumentations, Zhejiang University, Hangzhou 310058, China. ${ }^{4}$ Cancer Center, Zhejiang University, Hangzhou 310058, China. ${ }^{5}$ Laboratory of Gastroenterology, The Second Affiliated Hospital, Zhejiang University School of Medicine, Hangzhou 310029, China. ${ }^{6}$ The Cancer Hospital of the University of Chinese Academy of Sciences (Zhejiang Cancer Hospital), Institute of Basic Medicine and Cancer (IBMC),

Chinese Academy of Sciences, Hangzhou, Zhejiang 310022, China.

Received: 2 July 2021 Accepted: 30 September 2021

Published online: 27 November 2021

\section{References}

1. Sung H, Ferlay J, Siegel RL, Laversanne M, Soerjomataram I, Jemal A, et al. Global cancer statistics 2020: GLOBOCAN estimates of incidence and mortality worldwide for 36 cancers in 185 countries. CA Cancer J Clin. 2021. https://doi.org/10.3322/caac.21660.

2. Dekker E, Tanis PJ, Vleugels JLA, Kasi PM, Wallace MB. Colorectal cancer. Lancet. 2019. https://doi.org/10.1016/S0140-6736(19)32319-0.

3. Vinchhi P, Patel MM. Triumph against cancer: invading colorectal cancer with nanotechnology. Expert Opin Drug Deliv. 2021;18(9):1169-92.

4. Wu L, Ishigaki Y, Hu Y, Sugimoto K, Zeng W, Harimoto T, et al. $\mathrm{H}_{2} \mathrm{~S}$-activatable near-infrared afterglow luminescent probes for sensitive molecular imaging in vivo. Nat Commun. 2020. https://doi.org/10.1038/ s41467-020-14307-y.

5. Horrigan LA, Holohan CA, Lawless GA, Murtagh MA, Williams CT, Webster CM. Blueberry juice causes potent relaxation of rat aortic rings via the activation of potassium channels and the $\mathrm{H}_{2} \mathrm{~S}$ pathway. Food Funct. 2013. https://doi.org/10.1039/C2FO30205E. 
6. Pozsgai G, Batai IZ, Pinter E. Effects of sulfide and polysulfides transmitted by direct or signal transduction-mediated activation of TRPA1 channels. Br J Pharmacol. 2019. https://doi.org/10.1111/bph.14514.

7. Cao X, Wu Z, Xiong S, Cao L, Sethi G, Bian JS. The role of hydrogen sulfide in cyclic nucleotide signaling. Biochem Pharmacol. 2018. https://doi.org/10.1016/j.bcp.2017.11.011.

8. Szabo C, Ransy C, Módis K, Andriamihaja M, Murghes B, Coletta C, Olah G, et al. Regulation of mitochondrial bioenergetic function by hydrogen sulphide. Part I. Biochemical and physiological mechanisms. Br J Pharmacol. 2014;171(8):2099-122.

9. Chen S, Yue T, Huang Z, Zhu J, Bu D, Wang $X$, et al. Inhibition of hydrogen sulfide synthesis reverses acquired resistance to 5-FU through miR-215-5p-EREG/TYMS axis in colon cancer cells. Cancer Lett. 2019. https://doi.org/10.1016/j.canlet.2019.09.006.

10. Augsburger F, Randi E, Jendly M, Ascencao K, Dilek N, Szabo C. Role of 3-mercaptopyruvate sulfurtransferase in the regulation of proliferation, migration, and bioenergetics in murine colon cancer cells. Biomolecules. 2020. https://doi.org/10.3390/biom 10030447

11. Asimakopoulou A, Panopoulos P, Chasapis CT, Coletta C, Zhou Z, et al. Selectivity of commonly used pharmacological inhibitors for cystathionine-b-synthase (CBS) and cystathionine-g-lyase (CSE). Br J Pharmacol. 2013;169:922-32.

12. Wu D, Si W, Wang M, Lv S, Ji A, Li Y. Hydrogen sulfide in cancer: friend or foe? Nitric Oxide. 2015. https://doi.org/10.1016/j.niox.2015.08.004.

13. Szabo C, Coletta C, Chao C, Modis K, Szczesny B, Papapetropoulos A, et al. Tumor-derived hydrogen sulfide, produced by cystathionine-beta-synthase, stimulates bioenergetics, cell proliferation, and angiogenesis in colon cancer. Proc Natl Acad Sci USA. 2013. https://doi. org/10.1073/pnas.1306241110.

14. Sekiguchi A, Endo Y, Yamazaki S, Uchiyama A, Shimizu A, Motegi SI. Plasma homocysteine levels are positively associated with interstitial lung disease in dermatomyositis patients with anti-aminoacyl-tRNA synthetase antibody. J Dermatol. 2021. https://doi.org/10.1111/13468138.15602.

15. Li Y, Chen W, Qi Y, Wang S, Li L, Li W, et al. $H_{2} S$-scavenged and activated iron oxide-hydroxide nanospindles for MRI-guided photothermal therapy and ferroptosis in colon cancer. Small. 2020. https://doi.org/10 1002/smll.202001356.

16. Chang M, Hou Z, Jin D, Zhou J, Wang M, Wang M, Shu M, et al. Colorectal tumor microenvironment-activated bio-decomposable and metabolizable Cu2O@CaCO3 nanocomposites for synergistic oncotherapy. Adv Mater. 2020;32(43): e2004647.

17. He Q, Liu J, Liang J, Liu X, Ding Z, Tuo D, et al. Sodium acetate orientated hollow/mesoporous magnetite nanoparticles: facile synthesis, characterization and formation mechanism. Appl Sci. 2018. https://doi. org/10.3390/app8020292.

18. He Q, Tian Y, Wu Y, Liu J, Li G, Deng P, et al. Electrochemical sensor for rapid and sensitive detection of tryptophan by a $\mathrm{Cu}(2) \mathrm{O}$ nanoparticlescoated reduced graphene oxide nanocomposite. Biomolecules. 2019. https://doi.org/10.3390/biom9050176.

19. Tian Y, Deng P, Wu Y, Liu J, Li J, Li G, et al. High sensitive voltammetric sensor for nanomolarity vanillin detection in food samples via manganese dioxide nanowires hybridized electrode. Microchem J. 2020 https://doi.org/10.1016/j.microc.2020.104885.

20. Tian Y, Deng P, Wu Y, Li J, Liu J, Li G, et al. $\mathrm{MnO}_{2}$ nanowires-decorated reduced graphene oxide modified glassy carbon electrode for sensitive determination of bisphenol A. J Electrochem Soc. 2020. https:// doi.org/10.1149/1945-7111/ab79a7.

21. Wu Y, Deng P, Tian Y, Magesa F, Liu J, Li G, et al. Construction of effective electrochemical sensor for the determination of quinoline yellow based on different morphologies of manganese dioxide functionalized graphene. J Food Compost Anal. 2019. https://doi.org/10.1016/j.jfca. 2019.103280

22. Neveux L, Chiche D, Bazer-Bachi D, Favergeon L, Pijolat M. New insight on the $\mathrm{ZnO}$ sulfidation reaction: evidences for an outward growth process of the ZnS phase. Chem Eng J. 2012. https://doi.org/10.1016/j. cej.2011.09.019.

23. Catalano V, Turdo A, Di Franco S, Dieli F, Todaro M, Stassi G. Tumor and its microenvironment: a synergistic interplay. Semin Cancer Biol. 2013. https://doi.org/10.1016/j.semcancer.2013.08.007.
24. Liu D, Li B, Wu J, Liu Y. Sorbents for hydrogen sulfide capture from biogas at low temperature: a review. Environ Chem Lett. 2020;18(1):113-28.

25. Aksoy B, Atakan N, Aksoy HM, Tezel GG, Renda N, Ozkara HA, et al. Effectiveness of topical zinc oxide application on hypertrophic scar development in rabbits. Burns. 2013;36(7):1027-35.

26. Szabo C. Gasotransmitters in cancer: from pathophysiology to experimental therapy. Nat Rev Drug Discov. 2016. https://doi.org/10.1038/nrd 2015.1.

27. Kodela R, Nath N, Chattopadhyay M, Nesbitt D, Velázquez-Martínez C, Kashfi K. Hydrogen sulfide-releasing naproxen suppresses colon cancer cell growth and inhibits NF-KB signaling. Drug Des Devel Ther. 2015. https://doi.org/10.2147/DDDT.S91116.

28. De Cicco P, Sanders T, Cirino G, Maloy K, lanaro A. Helicobacter hepaticus hydrogen sulfide reduces myeloid-derived suppressor cell-mediated inflammatory response in a model of -induced colitis. Front immunol. 2018. https://doi.org/10.3389/fimmu.2018.00499.

29. Li M, Mao J, Zhu Y. New therapeutic approaches using hydrogen sulfide donors in inflammation and immune-response. Antioxid Redox Signal. 2021. https://doi.org/10.1089/ars.2020.8249.

30. Zhu H, Blake S, Chan KT, Pearson RB, Kang J. Cystathionine beta-synthase in physiology and cancer. Biomed Res Int. 2018. https://doi.org/10.1155/ 2018/3205125.

31. Teng Z, Li W, Tang Y, Elzatahry A, Lu G, Zhao D. Mesoporous organosilica hollow nanoparticles: synthesis and applications. Adv Mater. 2019. https://doi.org/10.1002/adma.201707612.

32. Sun J, Modi S, Liu Ke, Lesieur R, Buglass J. Kinetics of zinc oxide sulfidation for packed-bed desulfurizer modeling. Energy Fuels. 2007;21:1863-71.

33. Palmer B, Gutiérrez C, Gidas M, Berrouk AS, Mena Gawargy WH. Rate phenomena in the reaction of hydrogen sulfide with a zinc oxide-based sorbent. Chemistry. 2011. https://doi.org/10.1002/ep.10495.

34. Parsanathan R, Jain SK. Hydrogen sulfide increases glutathione biosynthesis, and glucose uptake and utilisation in C2C12 mouse myotubes. Free Radic Res. 2018. https://doi.org/10.1080/10715762.2018.1431626.

35. Bourgonje A, Offringa A, van Eijk L, Abdulle A, Hillebrands J, van der Voort $\mathrm{P}$, et al. $\mathrm{N}$-acetylcysteine and hydrogen sulfide in coronavirus disease 2019. Antioxid Redox Signal. 2021. https://doi.org/10.1089/ars.2020.8247.

36. Kim AD, Zhang R, Han X, Kang KA, Piao MJ, Maeng YH, et al. Involvement of glutathione and glutathione metabolizing enzymes in human colorectal cancer cell lines and tissues. Mol Med Rep. 2015. https://doi.org/10. 3892/mmr.2015.3902.

37. Massaad L, de Waziers I, Ribrag V, Janot F, Beaune P, Morizet J, et al. Comparison of mouse and human colon tumors with regard to phase I and phase II drug-metabolizing enzyme systems. Cancer Res. 1992;52:6567-75

38. Perry R, Greaves B, Rasberry U, Barranco S. Effect of treatment duration and glutathione depletion on mitomycin C cytotoxicity in vitro. Cancer Res. 1992;52:4608-12.

39. Chen X, Li J, Kang R, Klionsky DJ, Tang D. Ferroptosis: machinery and regulation. Autophagy. 2020. https://doi.org/10.1080/15548627.2020.1810918.

40. Sun Y, Zheng Y, Wang C, Liu Y. Glutathione depletion induces ferroptosis, autophagy, and premature cell senescence in retinal pigment epithelial cells. Cell Death Dis. 2018. https://doi.org/10.1038/s41419-018-0794-4.

41. Proneth B, Conrad M. Ferroptosis and necroinflammation, a yet poorly explored link. Cell Death Differ. 2019. https://doi.org/10.1038/ s41418-018-0173-9.

42. Cozza G, Rossetto M, Bosello-Travain V, Maiorino M, Roveri A, Toppo S, et al. Glutathione peroxidase 4-catalyzed reduction of lipid hydroperoxides in membranes: the polar head of membrane phospholipids binds the enzyme and addresses the fatty acid hydroperoxide group toward the redox center. Free Radical Biol Med. 2017. https://doi.org/10.1016/j. freeradbiomed.2017.07.010

43. Liang $C$, Zhang $X$, Yang $M$, Dong $X$. Recent progress in ferroptosis inducers for cancer therapy. Adv Mater. 2019. https://doi.org/10.1002/adma. 201904197.

44. Sun W, Tyurin V, Mikulska-Ruminska K, Shrivastava I, Anthonymuthu T, Zhai Y, et al. Phospholipase iPLA $\beta$ averts ferroptosis by eliminating a redox lipid death signal. Nat Chem Biol. 2021. https://doi.org/10.1038/ s41589-020-00734-x.

45. Dharmalingam P, Talakatta G, Mitra J, Wang H, Derry PJ, Nilewski LG, et al. Pervasive genomic damage in experimental intracerebral hemorrhage: 
therapeutic potential of a mechanistic-based carbon nanoparticle. ACS Nano. 2020. https://doi.org/10.1021/acsnano.9b05821.

46. Wei S, Qiu T, Yao X, Wang N, Jiang L, Jia X, et al. Arsenic induces pancreatic dysfunction and ferroptosis via mitochondrial ROS-autophagy-lysosomal pathway. J Hazardous Mater. 2020. https://doi.org/10.1016/j.jhazmat. 2019.121390

47. Wu Y, Zhang S, Gong X, Tam S, Xiao D, Liu S, et al. The epigenetic regulators and metabolic changes in ferroptosis-associated cancer progression. Mol Cancer. 2020. https://doi.org/10.1186/s12943-020-01157-x.

48. Protchenko O, Baratz E, Jadhav S, Li F, Shakoury-Elizeh M, Gavrilova O, et al. Iron chaperone poly $\mathrm{rC}$ binding protein 1 protects mouse liver from lipid peroxidation and steatosis. Hepatology. 2021. https://doi.org/10. 1002/hep.31328.

49. Gao M, Yi J, Zhu J, Minikes AM, Monian P, Thompson CB, et al. Role of mitochondria in ferroptosis. Mol Cell. 2019. https://doi.org/10.1016/j. molcel.2018.10.042

50. Du J, Zhou Y, Li Y, Xia J, Chen Y, Chen S, et al. Identification of frataxin as a regulator of ferroptosis. Redox Biol. 2020. https://doi.org/10.1016/j.redox. 2020.101483.

51. Prabhakar U, Maeda H, Jain RK, Sevick-Muraca EM, Zamboni W, Farokhzad $\mathrm{OC}$, et al. Challenges and key considerations of the enhanced permeability and retention effect for nanomedicine drug delivery in oncology. Cancer Res. 2013. https://doi.org/10.1158/0008-5472.CAN-12-4561.

52. Kanthi Y, de la Zerda A, Smith BR. Nanotherapeutic shots through the heart of plaque. ACS Nano. 2020. https://doi.org/10.1021/acsnano.0c002 45.

53. Wang S, Gao M, Ma B, Xi M, Kong F. Size-dependent effects of ZnO nanoparticles on performance, microbial enzymatic activity and extracellular polymeric substances in sequencing batch reactor. Environ Pollut. 2020. https://doi.org/10.1016/j.envpol.2019.113596.

\section{Publisher's Note}

Springer Nature remains neutral with regard to jurisdictional claims in pub-

lished maps and institutional affiliations.

- fast, convenient online submission

- thorough peer review by experienced researchers in your field

- rapid publication on acceptance

- support for research data, including large and complex data types

- gold Open Access which fosters wider collaboration and increased citations

- maximum visibility for your research: over $100 \mathrm{M}$ website views per year

At BMC, research is always in progress.

Learn more biomedcentral.com/submissions 